\title{
Exercise cardiovascular magnetic resonance: development, current utility and future applications
}

\author{
Thomas P. Craven $^{1 *} \mathbb{D}$, Connie W. Tsao ${ }^{2}$, Andre La Gerche ${ }^{3,4}$, Orlando P. Simonetti ${ }^{5}$ and John P. Greenwood
}

\begin{abstract}
Stress cardiac imaging is the current first line investigation for coronary artery disease diagnosis and decision making and an adjunctive tool in a range of non-ischaemic cardiovascular diseases. Exercise cardiovascular magnetic resonance (Ex-CMR) has developed over the past 25 years to combine the superior image qualities of CMR with the preferred method of exercise stress. Presently, numerous exercise methods exist, from performing stress on an adjacent CMR compatible treadmill to in-scanner exercise, most commonly on a supine cycle ergometer. Cardiac conditions studied by Ex-CMR are broad, commonly investigating ischaemic heart disease and congenital heart disease but extending to pulmonary hypertension and diabetic heart disease. This review presents an in-depth assessment of the various Ex-CMR stress methods and the varied pulse sequence approaches, including those specially designed for Ex-CMR. Current and future developments in image acquisition are highlighted, and will likely lead to a much greater clinical use of Ex-CMR across a range of cardiovascular conditions.
\end{abstract}

Keywords: Cardiovascular magnetic resonance, Exercise cardiovascular magnetic resonance, Stress cardiovascular magnetic resonance, Exercise stress, Treadmill cardiovascular magnetic resonance, Supine cycle ergometer

\section{Background}

Stress testing can be a pivotal tool for the diagnostic and prognostic assessment of cardiovascular disease. Historically for coronary artery disease (CAD), treadmill electocardiography (ECG) was the reference standard $[1,2]$. However, the use of stress cardiac imaging for exercise testing has significantly improved the diagnostic accuracy for CAD detection compared to exercise ECG alone [3-8]. Thus stress imaging is now the preferred investigation for CAD diagnosis in intermediate risk patients and a useful tool for prognostication and decision making $[9,10]$. Cardiovascular magnetic resonance (CMR) has several well established benefits over alternative imaging modalities, allowing a non-invasive comprehensive

\footnotetext{
* Correspondence: thomascraven@doctors.org.uk

'Leeds Institute of Cardiovascular and Metabolic Medicine, University of Leeds, Leeds, UK

Full list of author information is available at the end of the article
}

multi-parametric assessment, with few limitations from body habitus, no ionizing radiation [11], and is the noninvasive gold standard for bi-ventricular volume and functional assessment [12, 13]. Pharmacological stress CMR has become widely utilised clinically, demonstrating superiority over myocardial perfusion scintigraphy by single photon emission computed tomography (MPSSPECT) in the diagnosis $[14,15]$ and prognosis of CAD [16] and recently, a lower incidence of revascularization and non-inferiority in major adverse cardiac events compared to CAD management guided by coronary angiography with fractional flow reserve [17]. However, pharmacological stress has more adverse events than exercise stress, as demonstrated in stress echocardiography $[18,19]$, contraindications and side effects patients may not tolerate [20] and does not replicate the neurohormonal and haemodynamic changes associated with physical exercise. As such, current guidelines advise physical 
exercise as the preferred method for stress imaging, when feasible [21, 22]. Exercise imaging studies primarily focus on CAD, however exercise testing is an important decision making tool in numerous cardiac diseases including valvular heart disease [23] and congenital heart disease [24].

Despite the advantages of CMR as a modality and physical exercise advised first line, exercise CMR (ExCMR) is not widely used clinically. Limitations include difficulty with image acquisition and quality, the expense of commercially available CMR compatible exercise devices [25] and that exercise testing is technically more difficult than administering pharmacological stress [26]. This review will focus on the recent development of ExCMR as a technique, its current utility and challenges, and its potential future applications and technical developments.

\section{Exercise CMR - methodology and development}

Ex-CMR is performed either by exercising outside the scanner bore on a CMR compatible adjacent treadmill [27] or by exercising in the CMR scanner, most commonly using a supine cycle ergometer. Exercising in the CMR environment has safety implications, as patients require rapid removal from the magnet bore and scanner room to facilitate resuscitation in the event of cardiac arrest [28]. Exercise on a CMR compatible adjacent treadmill, utilising a Bruce protocol treadmill test, benefits from the safety of 12-lead ECG monitoring, essential for identifying ECG changes which may prompt test termination, but with the limitation of requiring rapid transfer to the CMR isocenter for post stress imaging. In-scanner Ex-CMR overcomes this limitation, as exercise can be performed in the scanner bore, with imaging performed during exercise or a brief cessation of exercise. However, CMR scanning during exercise creates several issues including increased physical and respiratory motion creating artefacts, ECG gating issues and cannot be monitored by 12-lead ECG [29]. Indeed accurate ST segment monitoring is not feasible within the CMR scanner bore due to the magnetohydrodynamic effect distorting the surface ECG [30]. ECG gating issues can occur at maximal heart rates and during exercise. At maximal heart rates this can be overcome with real time imaging after exercise cessation, as utilised in treadmill Ex-CMR [31], or with ungated real time imaging during maximal supine bicycle exercise [29]. Exercise inherently causes movement, which can result in image acquisition away from the initial planned slice location. Bulk movement can be reduced by using straps around the chest and anterior coil and by counselling/training the patient. However, meticulous image planning is essential to ensure appropriate stress slice localisation. Short axis cine imaging, for ventricular volumetric analysis, should be planned with sufficient slices beyond the base and apex, to account for movement. Repeating left ventricular (LV) and right ventricular (RV) outflow tract views after/ during exercise, with free breathing imaging, immediately prior to phase contrast imaging of the aorta or main pulmonary artery allows re-planning to account for movement that may have occurred whilst performing in-scanner exercise. Respiratory navigation can be performed to accommodate for respiratory motion and can be performed retrospectively with ungated real time CMR imaging by manually 'gating' respiration using a plethmysograph trace [29].

Numerous exercise CMR studies have been performed using varying methods, including treadmill exercise, supine cycle ergometer or supine stepper-stress, upright cycle ergometry in an open magnet, isometric handgrip exercise (IHG) and prone exercise using either knee flexion or extension with resistance from cables or nonferromagnetic weights. Similar to exercise echocardiography, the range of applications of Ex-CMR extends beyond CAD to a wide range of cardiac conditions. Each exercise method has inherent benefits and weakness (Table 1). Treadmill exercise, to date, has demonstrated the most clinical utility, being the only validated method for ischaemia detection, however, in-scanner supine cycle ergometer exercise has numerous publications in a broader range of cardiac conditions. Each exercise method will be reviewed including its benefits, limitations, published applications and the technological and imaging sequence developments that have occurred to overcome the described issues of performing Ex-CMR.

\section{Treadmill exercise CMR}

Directly analogous to treadmill stress echocardiography, treadmill Ex-CMR is performed to achieve the required exercise intensity/ target heart rate (THR). The patient is then rapidly transferred into the CMR scanner for post stress imaging. Treadmill Ex-CMR has progressed from exercising outside the scanner room [33], to the development of a CMR compatible treadmill to allow exercise to take place inside the scanner room [34] and eventually performed adjacent to the CMR scanner [27] (Fig. 1). For ischaemia studies, this progression has reduced the 'cooling off period' from peak stress to image acquisition, as even a $60-90 \mathrm{~s}$ delay in performing stress echocardiography image acquisition, has demonstrated recovery of ischaemic regional wall abnormalities and thus decreases the sensitivity of ischaemia detection [35, 36]. Numerous studies in exercise echocardiography have demonstrated the differences between peak and post stress imaging, specifically demonstrating that peak stress imaging has superior sensitivity and accuracy at detecting ischaemia than post stress imaging [35, 3740]. A direct 'head-to-head' comparison in stress 
Table 1 Characteristics and benefits of the varying exercise modalities used in exercise CMR

\begin{tabular}{|c|c|c|c|c|c|c|}
\hline \multirow[t]{3}{*}{$\begin{array}{l}\text { Exercise } \\
\text { type }\end{array}$} & Treadmill & Upright cycle ergometer & $\begin{array}{l}\text { Supine Cycle } \\
\text { ergometer }\end{array}$ & $\begin{array}{l}\text { Supine stepper } \\
\text { ergometer }\end{array}$ & Prone exercise & $\begin{array}{l}\text { Isometric } \\
\text { Handgrip }\end{array}$ \\
\hline & Outside MR scanner & \multicolumn{5}{|l|}{ Inside MR scanner } \\
\hline & Dynamic & Dynamic & Dynamic & Dynamic & Dynamic & Static \\
\hline $\begin{array}{l}\text { Common } \\
\text { applications }\end{array}$ & $\begin{array}{l}\text { Ischaemia testing } \\
\text { (Regional wall motion \& } \\
\text { perfusion) }\end{array}$ & Aortic/Pulmonary Flow & $\begin{array}{l}\text { Ventricular } \\
\text { volumes } \\
\text { Aortic/pulmonary } \\
\text { flow }\end{array}$ & $\begin{array}{l}\text { Ventricular } \\
\text { volumes } \\
\text { Aortic/ } \\
\text { pulmonary } \\
\text { flow }\end{array}$ & Spectroscopy & $\begin{array}{l}\text { Spectroscopy } \\
\text { Coronary } \\
\text { endothelial } \\
\text { function }\end{array}$ \\
\hline $\begin{array}{l}\text { Max } \\
\text { exercise } \\
\text { intensity }^{\mathrm{a}}\end{array}$ & Maximal & Light & Maximal & $\begin{array}{l}\text { Submaximal/ } \\
\text { Vigorous }\end{array}$ & Light-Moderate & Very-light \\
\hline \multirow[t]{3}{*}{ Benefits } & \multirow[b]{3}{*}{$\begin{array}{l}\text {-Patients more readily } \\
\text { achieve maximal } \\
\text { intensity exercise } \\
\text {-Diagnostic } 12 \text { lead ECG } \\
\text { performed during } \\
\text { exercise } \\
\text {-Treadmill test provides } \\
\text { separate prognostic data } \\
\text { - Maximal oxygen uptake } \\
\text { during exercise on CMR } \\
\text { adjacent treadmill } \\
\text { feasible } \\
\text {-Most natural and } \\
\text { tolerated form of } \\
\text { exercise }\end{array}$} & \multicolumn{5}{|l|}{ Allows imaging during exercise } \\
\hline & & \multicolumn{5}{|c|}{ Allows imaging at multpile exercise levels } \\
\hline & & $\begin{array}{l}\text {-Only modality with upright in- } \\
\text { scanner exercise } \\
\text {-Less claustrophobia in open } \\
\text { magnet scanner }\end{array}$ & $\begin{array}{l}\text {-Can be } \\
\text { performed to } \\
\text { maximal exercise } \\
\text { intensity in MR } \\
\text { bore. }\end{array}$ & $\begin{array}{l}\text {-Less leg } \\
\text { restriction than } \\
\text { cycle } \\
\text { ergometer }\end{array}$ & & $\begin{array}{l}\text {-Stable stress } \\
\text { heart rate } \\
\text {-Minimal } \\
\text { movement } \\
\text {-No magnet } \\
\text { bore } \\
\text { restriction }\end{array}$ \\
\hline \multirow[t]{2}{*}{ Weaknesses } & \multirow{2}{*}{$\begin{array}{l}\text { - Post stress imaging } \\
\text { allows heart rate } \\
\text { recovery before } \\
\text { imaging } \\
\text { - Logistically difficult to } \\
\text { image at multiple } \\
\text { exercise intensities }\end{array}$} & \multicolumn{5}{|c|}{ Unable to perform 12 lead ECG or accurate ST segment monitoring during in-scanner exercise } \\
\hline & & $\begin{array}{l}\text {-Uses open magnet scanner - low } \\
\text { field strength (low SNR), limited } \\
\text { availability, CMR feasible but non- } \\
\text { standard. } \\
\text {-Only published in minimal studies } \\
\text { to light intensity exercise. }\end{array}$ & $\begin{array}{l}\text {-Cycling can be } \\
\text { restricted by } \\
\text { magnet bore } \\
\text { diameter }\end{array}$ & $\begin{array}{l}\text { - Lower } \\
\text { intensity } \\
\text { exercise than } \\
\text { cycle } \\
\text { ergometer }\end{array}$ & $\begin{array}{l}\text { - Uncomfortable } \\
\text { form of } \\
\text { exercise } \\
\text { - Modest } \\
\text { exercise } \\
\text { feasible } \\
\text { - Logistically } \\
\text { difficult to } \\
\text { increase } \\
\text { resistance }\end{array}$ & $\begin{array}{l}\text {-Atypical } \\
\text { form of } \\
\text { exercise } \\
\text { - Limited } \\
\text { increase in } \\
\text { heart rate }\end{array}$ \\
\hline
\end{tabular}

${ }^{a}$ Highest exercise intensity achieved in published research, with intensities defined by American College of sports medicines guidelines [32]. SNR $=$ signal-to-noise ratio

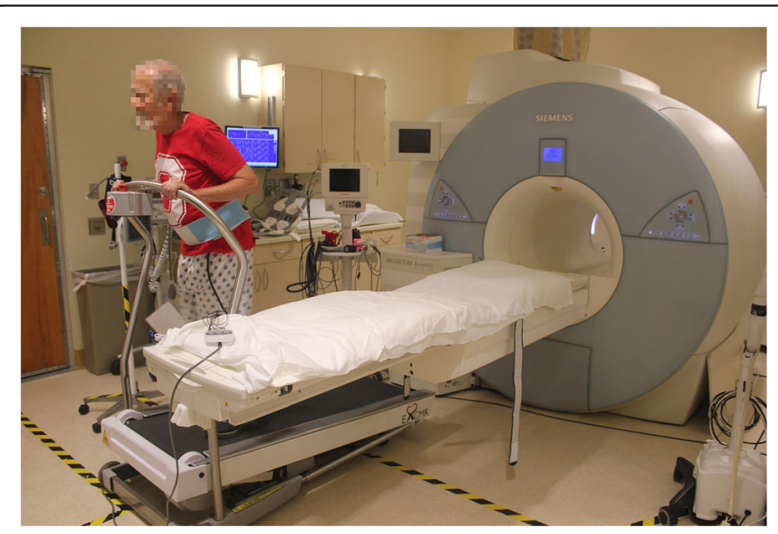

Fig. 1 Cardiovascular magnetic resonance (CMR) compatible scanner adjacent treadmill, developed and utilised in ischaemia studies by the Ohio State University Research group [27], reduces transfer times for post stress CMR imaging, whilst still allowing a diagnostic 12-lead ECG treadmill test and a simultaneous maximal oxygen uptake test, if required echocardiography demonstrated that peak stress supine bicycle echocardiography was superior to post stress treadmill echocardiography in ischaemia detection [41]. Consequently, stress echocardiography guidelines recommend post stress imaging be accomplished in under $60 \mathrm{~s}$ [26]. However, as CMR can detect ischaemia by assessing myocardial perfusion in addition to assessing wall motion abnormalities, treadmill Ex-CMR may be less time sensitive post exercise cessation than treadmill echocardiography. Varying transfer times have been achieved in treadmill Ex-CMR studies (Table 2) [27, 31, $33,34,42-45]$. Since progression to a CMR compatible treadmill adjacent to the scanner, all studies demonstrate scan initiation in under $30 \mathrm{~s}$, as shown in Video 1 (with the exception of La Fountain et al. in which removal of the face mask assessing oxygen uptake prolonged transfer time [44]) and cine imaging completion in under $60 \mathrm{~s}[42,43,45]$. 


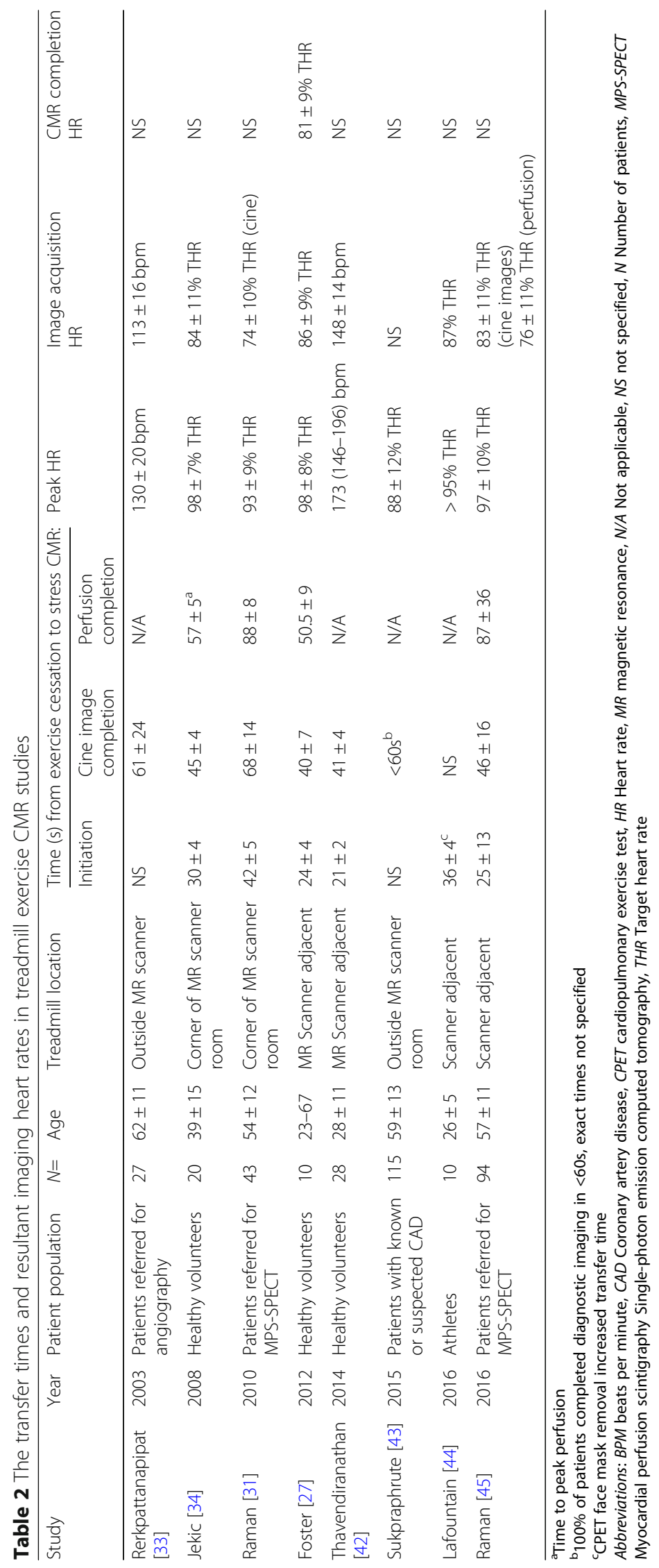




\section{Exercise protocol}

The current treadmill Ex-CMR protocol entails performing initial resting survey imaging and LV cine imaging. The patient is removed from the scanner bore for a supine 12 lead ECG, then transfers to the scanner adjacent CMR compatible treadmill for an initial standing 12 lead ECG and subsequently performs a symptom limited Bruce protocol treadmill test. After achieving THR > $0.85 \times$ (220-age), the patient is rapidly transferred to the CMR scanner for free-breathing multiplane cine imaging. $0.1 \mathrm{mmol} / \mathrm{kg}$ gadolinium contrast is injected prior to stress perfusion imaging, after which the CMR scanner table is removed from the magnet bore to allow 6-8 min of recovery with 12-lead ECG and blood pressure monitoring. The imaging is completed with rest perfusion and late gadolinium enhanced sequences [45]. This protocol is compared with adenosine/dobutamine pharmacological stress CMR imaging in Fig. 2 [20, 45, 46].

CMR imaging sequences used after treadmill exercise have developed, to hasten acquisition and remove breath holding. Initially, retrospectively gated sequences were used with short breath holds to acquire short axis cine imaging for regional wall motion abnormality assessment [33]. The use of real time balanced steady state free precession (bSSFP) imaging with either TSENSE or GRAPPA acceleration, allowed progression to free breathing acquisition of short and long axis LV cine images for regional wall motion assessment [31, 34, 42, 44, 45]. Additionally, perfusion imaging has been performed in several studies, after cine image acquisition, using saturation recovery hybrid gradient echo, echo planar imaging [31, 45].

Treadmill stress CMR offers several benefits over other Ex-CMR modalities (Table 1). Patients often tolerate treadmill exercise greater than cycling, as it is a more natural form of exercise [47] and some patients are unable to cycle [26]. Patients more readily achieve $>85 \%$ age predicted THR on the treadmill compared to nonweight bearing exercise $[41,48]$. The treadmill test itself provides diagnostic and prognostic information independent of imaging [31, 49-51] and a traditional

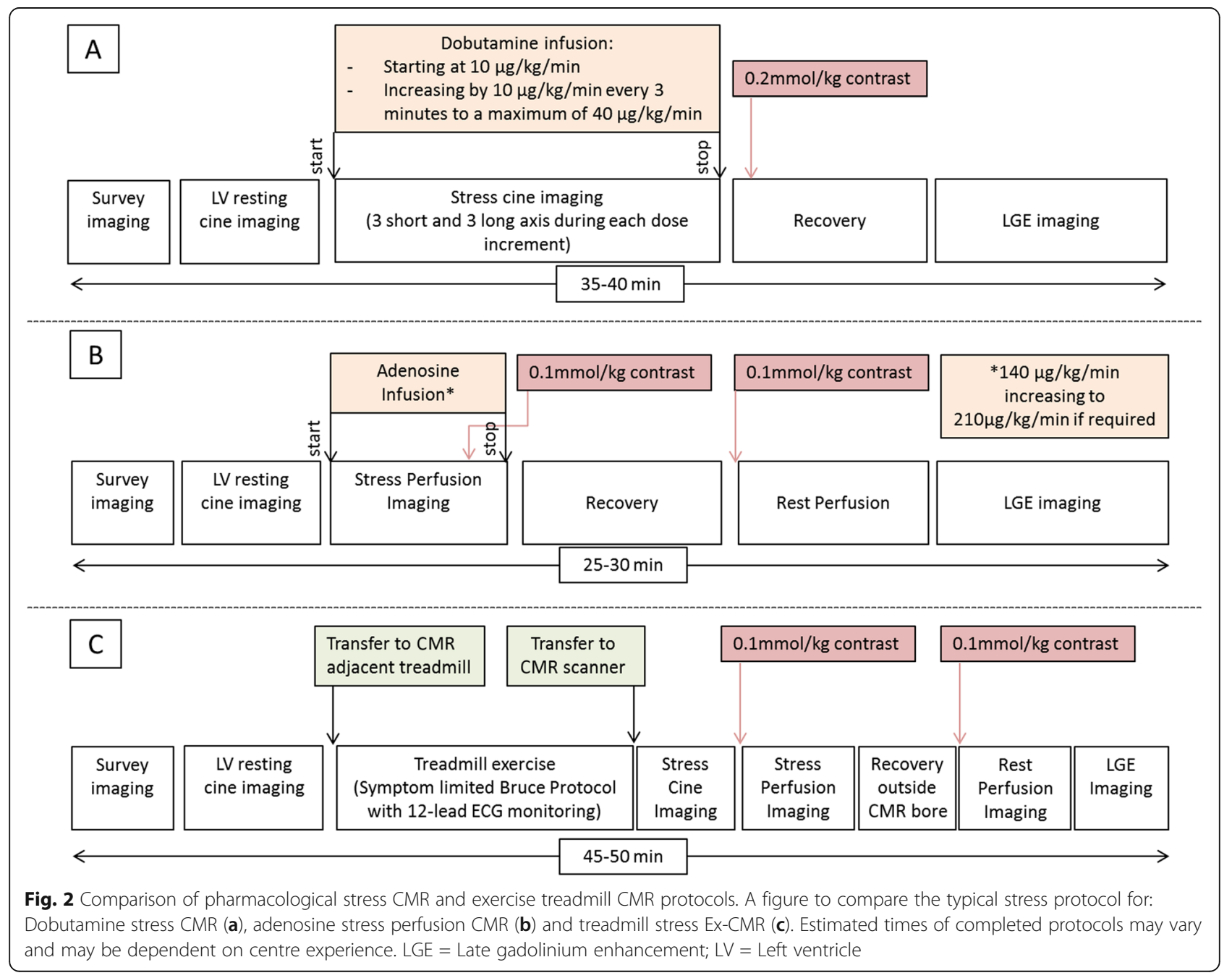


maximal oxygen uptake assessment is feasible during treadmill exercise within the CMR scanner room [44]. Treadmill stress incorporates a 12-lead ECG exercise test, which is diagnostic even on a CMR adjacent treadmill, compared with non-diagnostic ECG monitoring performed when exercising inside the CMR scanner [52]. This monitoring may be vital to assess for ST segment changes or arrhythmias which can be absolute indications to terminate an exercise test during ischaemia testing [53]. Therefore treadmill Ex-CMR is arguably the safest Ex-CMR methodology to assess CAD. There are limitations to treadmill Ex-CMR. Imaging at numerous exercise intensities is logistically difficult and post stress imaging restricts the time available before a decline in heart rate, thus limiting applications to those achievable within a few minutes. The transfer process also interrupts the advised post-exercise ECG observation period [53]. However, whilst CMR stress perfusion is feasible using the supine cycle ergometer in healthy subjects [54], treadmill Ex-CMR is currently the only Ex-CMR modality to demonstrate utility in ischaemia detection in CAD patients, with clinical evidence from single and multi-centre studies [31, 33, 43, 45].

\section{In-scanner exercise CMR}

In-scanner Ex-CMR can be performed by supine cycle or stepper ergometer, upright cycling in an open magnet, exercise in the prone position or using isometric handgrip; each method is reviewed in Table 1. Inscanner exercise overcomes the main limitation of treadmill Ex-CMR of heart rate reductions between exercise cessation and image acquisition. Imaging during exercise does however have difficulties. Exercise invariably creates movement, increased respiratory motion and interference to the surface ECG, all of which increase with increasing workload. Movement can be reduced with the use of straps or harnesses, but not entirely, especially at higher levels of exercise. Breath held images can be performed during exercise but are non-physiological and difficult at higher exercise intensities [29]. Imaging during free breathing can cause significant though plane motion, making obtaining reliable flow measurements difficult, with the pulmonary trunk especially challenging due to its short length before bifurcation [55]. ECG interference during exercise can create ghosting artefacts with gated images and as previously described, accurate 12 lead ECG monitoring with ST segment analysis cannot be performed during in-scanner exercise $[29,30,52]$. Finally, reaching maximal heart rate is more difficult with supine exercise compared with upright exercise; this is well documented in stress echocardiography with comparisons between treadmill and supine cycle exercise $[41,48,56,57]$. One explanation is early termination due to leg fatigue [41,
53], thus $\mathrm{VO}_{2 \max }$ is often $10-20 \%$ lower in supine cycle exercise than treadmill exercise. Despite this, evidence from stress echocardiography demonstrates equivalency or superiority in detecting ischaemia over post stress treadmill exercise [41, 48, 56]. Indeed, comparatively higher blood pressure attained during supine ergometry $[41,48,57,58]$, results in a similar rate-pressure product to treadmill exercise, such that THR during supine exercise are generally lower when compared to the same exercise intensity in the upright position. Despite the described difficulties of performing in-scanner exercise CMR, techniques have been adapted, with the use of the supine cycle ergometer, such that it is possible to perform in-scanner Ex-CMR to maximal intensity heart rates with imaging during exercise to assess either biventricular function or great vessel flow $[29,55]$, but often not both, due to time constraints of scanning at incremental levels during or immediately post exercise.

\section{Supine ergometer exercise CMR}

The first published use of a CMR compatible cycle ergometer was in 1995 using a $0.5 \mathrm{~T}$ whole body scanner to measure exercise changes in aortic flow [59]. Studies utilising commercially produced cycle ergometers followed in 1998 with the use of the Lode BV MR compatible ergometer (Fig. 3) on a 1.5 T CMR scanner [60]. Whilst the majority of Ex-CMR cycle ergometer studies use this system $[29,54,55,60-80]$, some institutions have created custom made CMR compatible cycle ergometers $[25,81,82]$. Other approaches include the supine CMR compatible 'stepper' ergometer, that utilises an up/down motion, such as the Lode BV up/down ergometer [8385], Ergospect cardio-stepper [86] and custom built supine steppers as demonstrated in Fig. 4 [87]. Studies

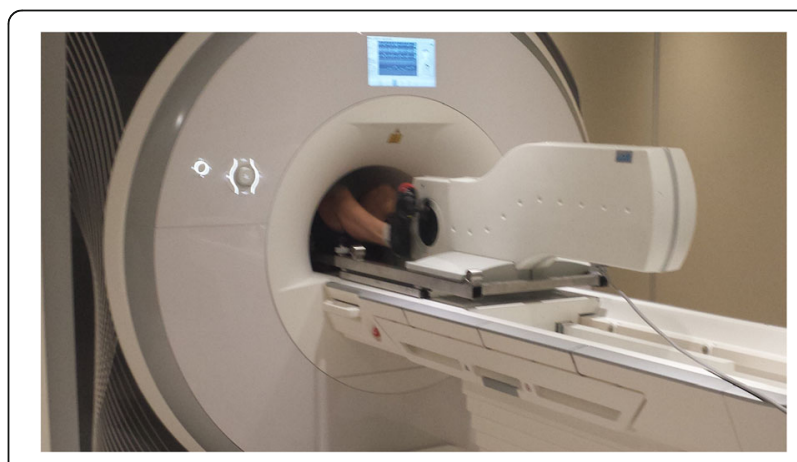

Fig. 3 Lode BV supine cycle ergometer during in-scanner supine exercise cardiac magnetic resonance. The Lode BV supine cycle ergometer allows in-scanner exercise, up to maximal exercise intensity, during CMR scanning, as demonstrated by La Gerche et al. [29]. The ergometer attaches firmly to the CMR scanner bed by screw attachments and is safe to use in CMR scanners up to $3 \mathrm{~T}$. The patients' feet attach into the stirrups and strap securely in place. Resistance can be altered manually in 1-watt intervals. This ergometer is the most utilised modality in Ex-CMR research studies 


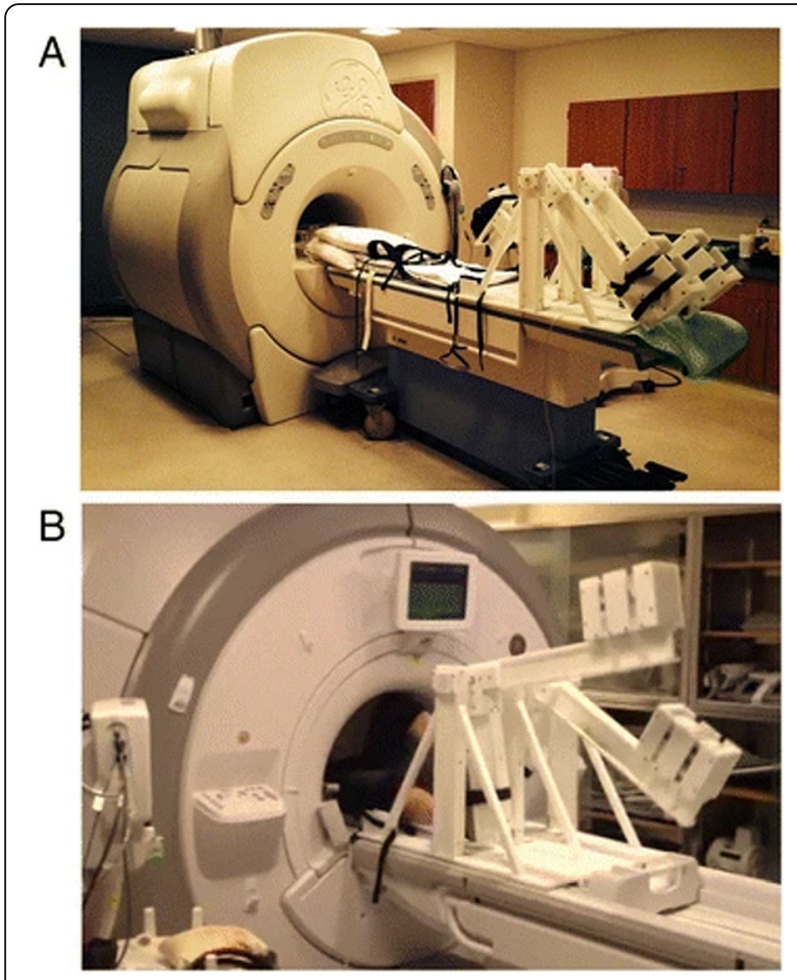

Fig. 4 Custom supine stepper ergometer. An example of a supine stepper ergometer utilised in research at the University of Wisconsin [87]. a. The ergometer outside the CMR-scanner. b- The ergometer in use. The ergometer allows for exercise via an up/down motion, a technique which is reported to cause less movement artefact than the cycle ergometer at the cost of less muscle mass recruitment and thus lower achievable maximal heart rates

using stepper systems report the benefit of reduced upper body motion, thus reduced motion artefact, and less restriction of leg movement compared with cycle ergometers. However, the up/down motion recruits less muscle mass than the cyclical motion. Thus no study has demonstrated supine 'stepper' ergometer Ex-CMR to maximal intensity, as has been demonstrated with supine cycle ergometers (Video 2) [29].

\section{Exercise protocol}

Exercise protocols used with supine cycle ergometer ExCMR vary depending upon the aims of the study/investigation. An example protocol is presented in Fig. 5. The number of stages of exercise is variable depending upon the aims. A typical protocol often entails a period of supine cycling with no resistance $(0 \mathrm{~W})$ on the ergometer, to allow the patient to accustom to the cycling positon and the advised cadence. This is followed by a graduated increase in resistance, for example by $25 \mathrm{~W}$ every $2 \mathrm{~min}$, until THR is achieved. However, in athletes a faster increase in resistance may be advised. The resistance is then maintained whilst at the specific exercise intensity heart rate. Indeed minute changes in resistance can be made, if required, to ensure tight control of heart rate during scanning. Once THR has been maintained for 60 s CMR imaging will commence. After completion of a specified exercise intensity stage, the process of 'ramping up' resistance, acquiring a stable THR prior to imaging and maintaining that THR during imaging is repeated for each exercise stage required.

\section{Ventricular volumes}

Cycle ergometer Ex-CMR ventricular volume assessment has progressed from imaging during exercise cessation with breath holding [25, 67, 70-72, 81], breath holding during exercise $[82,86]$, free breathing with exercise cessation $[54,64,66]$, to free breathing during continuous exercise $[29,83]$. Initial studies utilised turbo field echo planar imaging (EPI) with retrospective gating to acquire short axis cine imaging for biventricular volumes during exercise [67, 70, 71]. Subsequent studies using retrospective ECG gating have used balanced steady state free precision (bSSFP) sequences [25, 81, 82, 88, 89]. Recently, an Ex-CMR study used a $3 \mathrm{~T}$ scanner to assess LV volumes similarly used bSSFP sequences to acquire 4 chamber and 2-chamber cines to calculate LV function via Simpson's bi-plane method [86].

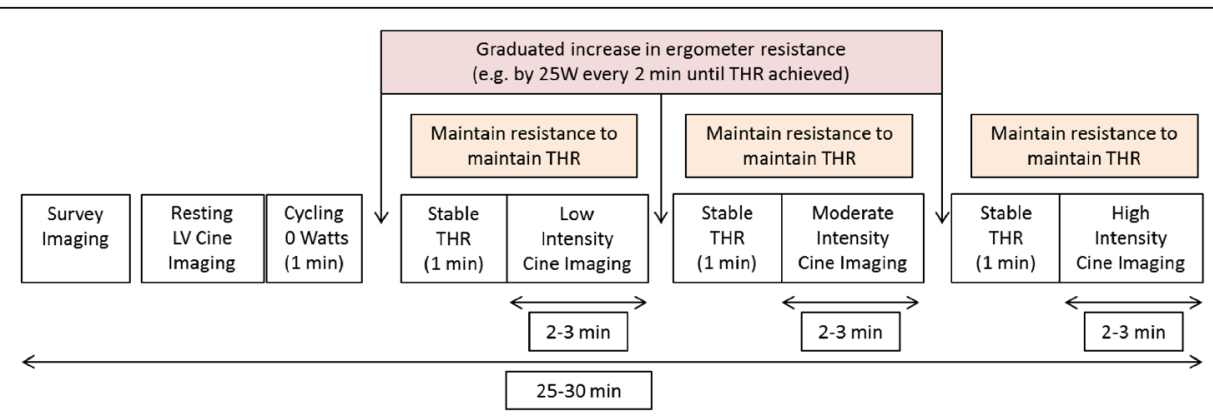

Fig. 5 Example of a supine bicycle Ex-CMR protocol. In-scanner Ex-CMR protocols may vary depending on indication, number of exercise stages required and participant fitness. Participants with superior cardiovascular fitness may benefit from shorter intervals between, or more aggressive, increases in resistance to achieve the target heart rate (THR) before leg fatigue. Using the Lode BV supine cycle ergometer, small alterations in resistance are possible, which can assist a tight control of THR 
To date, published retrospective gating techniques have not performed image acquisition with free breathing during exercise; this has been achieved with real time techniques. Lurz et al. first demonstrated the feasibility of imaging with free breathing during continuous exercise, assessing biventricular volume and function in healthy subjects. A radial $k-t$ SENSE real-time sequence demonstrated higher temporal resolution short axis cine images than a standard vendor supplied real time sequence in patients exercised to submaximal intensity [83]. Recently, a re-binning real time sequence with automated motion correction showed similar LV volumes, but improved signal-to-noise ratio (SNR) and temporal resolution than conventional real time technique during Ex-CMR to moderate intensity [90]. Real time imaging enables free breathing during Ex-CMR, however as the ECG is required to retrospectively reconstruct the images, it still suffers from gating issues at maximal exercise intensities. Indeed patients in the re-binning study were excluded as the images could not be reconstructed due to ECG interference [90]. Le et al. preferred exercise cessation with a real time sequence, to overcome ECG interference, to assess patients exercised to fatigue [66].

Reliable biventricular assessment during maximal exercise has been achieved by La Gerche et al. with the development of an ungated real time sequence (Fig. 6). Video 2 demonstrates in-scanner exercise and resultant cine imaging by this technique. The technique utilises specialized in-house software to compensate for respiratory motion which overcame the issue of excessive ECG artefact encountered during high intensity exercise with the comparator gated sequence. The cardiac output derived by this technique was validated against the direct Fick method with excellent agreement [29]. Although a limitation of this approach is prolonged post processing time and the requirement for bespoke in-house analysis software to synchronize the ECG and respiratory movement with the images, it is the only method to date to allow accurate biventricular quantification during maximal exercise and has since been utilised in a number of clinical studies [62, 63, 65, 73, 76, 77, 80].

It should be noted that the physiological response to exercise can differ depending on exercise type (aerobic/ anaerobic/dynamic) and position (upright/semi-supine/ supine) [53]. Previous non-CMR exercise studies have published contradicting LV end diastolic volume (EDV) responses to supine exercise, demonstrating an increase [91], a decrease [92] or no significant change [93-95] in EDV with exercise. However, a recent meta-analysis of LV function during supine Ex-CMR, involving a pooled analysis of 16 studies, demonstrated a significant rise in LV ejection fraction (EF) with exercise, driven by a fall in end systolic volume (ESV), whilst EDV remained unchanged [86].

\section{Flow acquisition}

Ex-CMR studies for flow assessment began by imaging during cessation of exercise and have progressed to free breathing acquisition during continuous exercise. ExCMR studies have predominantly assessed aortic and/or pulmonary artery flow, however flow assessment of the superior vena cava (SVC), left and right pulmonary arteries and all four pulmonary veins are feasible [96]. Inferior vena cava (IVC) flow assessment via Ex-CMR is challenging, owing to significant diaphragmatic movement during exercise, however has been achieved using real time phase contrast imaging with a novel respiratory compensation protocol that allows accurate assessment of the respiratory cycle via assessing chest wall motion [97]. Ex-CMR flow assessments were first performed in 1995 at $0.5 \mathrm{~T}$ using spiral EPI with breath holds after cessation of exercise to demonstrate increases in descending thoracic aorta flow, images were low resolution and heart rates equivalent of low exercise intensity [59]. Faster imaging techniques were adopted to reduce breath-hold times, allowing flow imaging after cessation of higher intensities of exercise, initially with the use of EPI in healthy subjects [68] and subsequently patients with congenital heart disease [67, 98].

Ex-CMR flow acquisition with free breathing during exercise was first performed by Niezen et al. in 1998 using retrospectively gated phase contrast velocity encoding during low intensity exercise [60], and subsequently during moderate exercise intensity $[69,74]$ and post exercise cessation [96]. Retrospective gating via pulse oximetry is commonly used to overcome ECG gating artefact at higher exercise intensities [60, 69].

Real time flow imaging techniques have been used successfully in Ex-CMR with the aid of post hoc analysis, with either in-house plug-ins for open source software or in-house developed specialist software. Steeden et al. used a spiral phase contrast real time sequence accelerated with sensitivity encoding (SENSE) to acquire aortic flow and a radial KT SENSE sequence to assess LV volumes, during light/moderate exercise on the Lode BV (Up/Down) ergometer. Aortic flows acquired by the real time technique had good agreement at rest with a standard 2D retrospective free breathing flow acquisition technique and at rest and during exercise with the stroke volume from LV volumes [99]. The same research group then utilised real-time unaliasing by Fourier-encoding the overlaps using the temporal dimension and sensitivity encoding spiral phase-contrast magnetic resonance sequence (UNFOLDed-SENSE) in subsequent studies. Initially the UNFOLDed-SENSE aortic flow sequence was used in a CMR augmented cardiopulmonary exercise test (CMR-CPET) to demonstrated feasibility of CMR-CPET in healthy adult subjects [84] and subsequently in combination with real time k-t SENSE short 


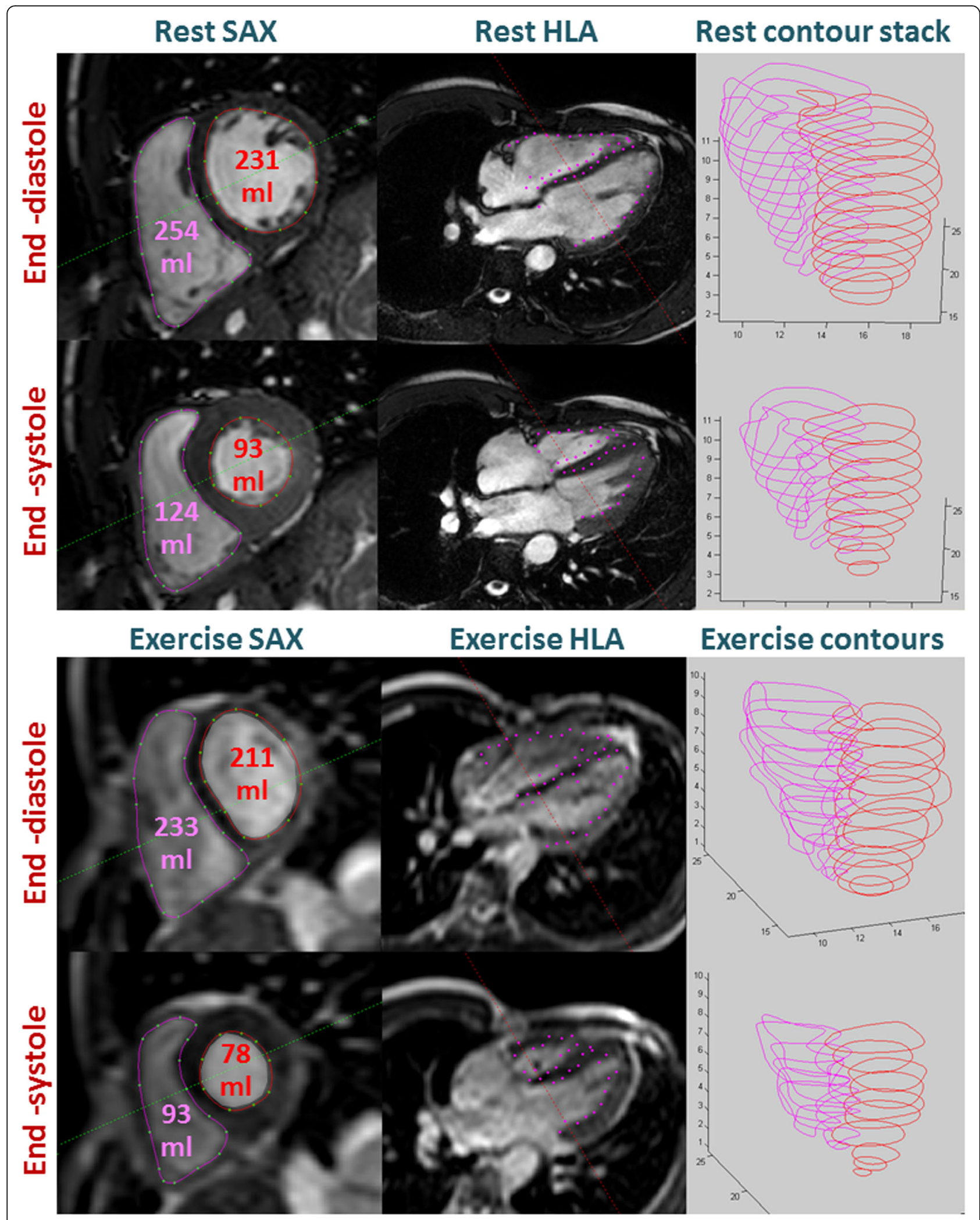

Fig. 6 Example of real-time ungated CMR imaging at rest and during maximal exercise. Real-time ungated biventricular volume assessment methodology as developed by La Gerche et al. and subsequently utilised in numerous subsequent clinical studies 
axis cines to perform CMR-CPET in paediatric healthy controls, repaired tetralogy of Fallot (ToF) and pulmonary artery hypertension patients [85]. A limitation of this continuous flow technique, highlighted by the authors, is the need to continuously measure flow to guarantee acquisition of data at peak exercise. This results in acquiring $\leq 25,000$ frames of flow images and therefore creates a significant reconstruction and post processing problem. As such, the reconstruction requires an online graphics processing unit reconstruction system and inhouse post processing tool to cope with the volume of data [85]. Studies by Aschenfeldt and Heiberg et al. similarly used real time flow acquisition but with fast EPI and a half scan factor of 0.6, with analysis on in-house developed specialist software. The technique allowed aortic and pulmonary flow acquisition at numerous exercise levels and to 'true' submaximal intensity (> 85\% age predicted maximum heart rate ), having being used to assess healthy subjects and patients with surgically repaired ventricular septal defects (VSD) [55, 61]. Recently, ungated real time biventricular volume and aortic and pulmonary flows were performed during exercise to moderate exercise intensity in healthy subjects and patients with pulmonary arterial hypertension, the flow volumes acquired were similar to stroke volumes acquired from biventricular volumes [100].

\section{Upright cycle ergometer}

Cheng et al. demonstrated the feasibility of assessing pulmonary artery flow during continuous exercise to moderate intensity in adults and children in a $0.5 \mathrm{~T}$ vertical open bore scanner [101]. Although upright cycling may be more tolerated than supine exercise, it requires the use of an open low field CMR scanner, with benefits of easing claustrophobia, but inherent issues of lower SNR. CMR is feasible at lower field strengths [102], however, although the scanners are commercially available they are not in mainstream use, as such very few ExCMR studies have utilised this modality.

\section{Isometric handgrip stress CMR}

Isometric exercise involves the contraction of skeletal muscle without the elongation of the muscle, as such is also called static exercise [103]. This is feasible during CMR by IHG or isometric bicep exercise [104]. IHG exercise comprises the constant squeezing of a lever on a hand dynamometer, generally to a percentage of the subjects maximum force. The technique only allows for modest increases in heart rate, typically $10-20 \mathrm{bpm}$ above resting rates, but causes minimal movement. As such the technique has mainly been used for CMR spectroscopy (MRS) or coronary artery flow imaging where minimal movement artefact is pivotal and minimal heart rate increases are acceptable. Weiss et al. performed the seminal work with IHG-Ex CMR, developing the ${ }^{31} \mathrm{P}$ CMR spectroscopy (CMRS) stress test which remarkably can detect ischaemia in patients with CAD, despite minimal stress and increases in heart rate [105].

\section{Prone exercise CMR}

Prone Ex-CMR was first employed by Conway et al. who performed Ex-CMR studies using knee extension with a custom system of straps, cables, pulleys and weights [106]. Numerous subsequent Ex-CMR studies have similarly used prone Ex-CMR performing alternative knee flexion with ankle weights [107-109]. Low-moderate intensity exercise is feasible by this approach, with the most significant response from the custom knee extension system by Conway et al., with a mean stress heart rate of $119 \mathrm{bpm}$. This technique has other inherent limitations; exercising whilst prone is an unnatural form of exercise which uses weights or resistance bands attached to the legs, increasing the resistance can be labour intensive, requiring alterations during exercise/scanning or exercise cessation. Prone Ex-CMR often requires an auditory cue from a metronome to determine work speed, however if this isn't strictly adhered to, then the exact workload is unknown. As such, only Conway et al. employed incremental resistance by increasing the attached weights to the pulley system used. As such, prone Ex-CMR is not ideal to assess incremental levels of exercise intensity or where strict heart rate increases or levels are required.

\section{Exercise CMR in specific disease conditions}

Ex-CMR has been utilised to study a wide range of cardiovascular pathology from CAD to potential cardiomyopathic conditions and structural/congenital heart disease. The following provides an overview of the more common disease areas investigated.

\section{Coronary artery disease}

Numerous studies have assessed regional wall motion and/or myocardial perfusion with Ex-CMR, all utilising treadmill exercise with post-stress imaging to achieve this (Table 3) [27, 31, 33, 34, 42, 44, 45]. Supine cycle ergometer myocardial stress perfusion has been demonstrated as feasible in healthy subjects [54] but has not yet been utilised to assess patients with CAD. The original treadmill work assessed 27 patients referred for coronary angiography with treadmill stress CMR and demonstrated a sensitivity and specificity of 79 and $85 \%$ respectively, for detecting stenosis (>70\%) [33]. The Ohio State University research group developed a CMR compatible treadmill [34] and utilised this in the EXACT trial [45]. The EXACT trial (exercise CMR's accuracy for cardiovascular stress testing) is a multicentre prospective observational study. Four participating centres recruited 
Table 3 Features and findings of treadmill exercise Cardiac MRI studies in coronary artery disease

\begin{tabular}{|c|c|c|c|c|c|}
\hline Study & Patient population & $\mathrm{n}$. & $\begin{array}{l}\text { Mean } \\
\text { Age } \\
\text { (years) }\end{array}$ & $\begin{array}{l}\text { Treadmill } \\
\text { location }\end{array}$ & Findings \\
\hline $\begin{array}{l}\text { Rerkpattanapipat } \\
\text { (2003) [33] }\end{array}$ & $\begin{array}{l}\text { Patients referred for } \\
\text { coronary angiography }\end{array}$ & 27 & $62 \pm 11$ & $\begin{array}{l}\text { Outside scanner } \\
\text { room }\end{array}$ & $\begin{array}{l}\text { Detected coronary artery stenosis }>70 \% \text { on coronary } \\
\text { angiography with sensitivity and specificity of } 79 \% \& 85 \% \text {. }\end{array}$ \\
\hline $\begin{array}{l}\text { Raman (2010) } \\
\text { [31] }\end{array}$ & $\begin{array}{l}\text { Patients referred for } \\
\text { SPECT }\end{array}$ & 43 & $54 \pm 12$ & $\begin{array}{l}\text { MR scanner } \\
\text { room corner }\end{array}$ & $\begin{array}{l}\text { Exercise stress CMR is feasible with cine wall motion and perfusion } \\
\text { assessment and has moderate agreement with SPECT }(K=0.58)\end{array}$ \\
\hline $\begin{array}{l}\text { Sukpraphrute } \\
\text { (2015) [43] }\end{array}$ & $\begin{array}{l}\text { Patients with known } \\
\text { or suspected CAD }\end{array}$ & 115 & $59 \pm 13$ & $\begin{array}{l}\text { Outside scanner } \\
\text { room }\end{array}$ & $\begin{array}{l}\text { Treadmill Ex-CMR RWMA assessment identified those at risk of future } \\
\text { adverse events (myocardial infarction, death, unstable angina prompting } \\
\text { admission) } 47 \% \text { with RWMA vs } 17 \% \text { without }\end{array}$ \\
\hline $\begin{array}{l}\text { Raman (EXACT } \\
\text { trial) } \\
\text { (2016) [45] }\end{array}$ & $\begin{array}{l}\text { Patients referred for } \\
\text { SPECT }\end{array}$ & 94 & $59 \pm 13$ & Scanner adjacent & $\begin{array}{l}\text { Treadmill stress CMR demonstrated a stronger correlation with } \\
\text { coronary angiography and superior specificity, sensitivity, positive } \\
\text { and negative predictive values for }>70 \% \text { stenosis at angiography } \\
\text { than treadmill SPECT }\end{array}$ \\
\hline
\end{tabular}

Abbreviations: CAD coronary artery disease, CMR cardiovascular magnetic resonance, RWMA regional wall motion abnormality, SPECT single photon emission computed tomography,

210 patients who were clinically referred for treadmill radionuclide single photon emission computed tomography (SPECT) and directly compared this with treadmill stress CMR. Patients had a rest ${ }^{99 \mathrm{~m}}$ Tc SPECT rest scan followed by resting CMR cine images. An in room treadmill stress test was then performed with ${ }^{99} \mathrm{~m}$ Tc tracer injected at peak stress. Patients were then rapidly transferred to the CMR scanner for CMR stress images, including cine and myocardial perfusion imaging. Stress SPECT images were subsequently performed in an adjacent gamma camera. All images were acquired in the same day from the same treadmill stress. Ninety-four of the patients had coronary angiography (X-ray or CT coronary angiography). This multi-centre trial demonstrated superiority of Ex-CMR over exercise SPECT for identifying $>70 \%$ at coronary angiography. Sensitivity, specificity, positive and negative predictive values for ExCMR were 78.6, 98.7, 91.7 and 96.3\% respectively, compared to 50, 93.7, 58.3 and $91.5 \%$ respectively for exercise SPECT. The EXACT trial was the first, and to date the only, multicentre Ex-CMR trial and demonstrated the diagnostic capabilities and clinical utility of treadmill Ex-CMR in CAD. The initial and downstream costs of treadmill Ex-CMR have being assessed by the recently completed and under review, multicentre EXACTCOST trial, which randomised patients to either treadmill stress SPECT or treadmill Ex-CMR. Treadmill ExCMR has similarly shown a promising comparison with exercise echocardiography in a pilot study of 28 patients, with Ex-CMR showing more myocardial segments being adequately visualised than by exercise echo [42]. In addition to CAD diagnosis, treadmill stress Ex-CMR has potential prognostic utility in predicting adverse events in those with known or suspected CAD. In a study of 115 patients with an indication for stress imaging, wall motion abnormalities were assessed at rest and post treadmill stress via Ex-CMR. The presence of stress induced regional wall motion abnormalities on treadmill
Ex-CMR better identified those at risk of future events (death, myocardial infarction \& unstable angina prompting admission) when compared to exercise ECG alone [43].

A recent supine cycle Ex-CMR feasibility study demonstrated post exercise T1 mapping could be a surrogate marker in detecting myocardial blood flow. In 14 CAD patients, post exercise $\mathrm{T} 1$ reactivity was associated with the severity of myocardial perfusion defect on MPSSPECT. Therefore, Ex-CMR T1 mapping shows potential for detecting myocardial ischaemia [110].

Ex-CMR studies using IHG stress can reproducibly assess coronary artery endothelial function by assessing coronary artery cross-sectional area change and coronary flow by velocity encoded CMR [111]. Studies have demonstrated endothelial dysfunction in CAD in the form of paradoxical vasoconstriction with exercise [112], assessed the reproducibility of this technique [113] and shown that the normal vasodilatory response of healthy coronary arteries is mediated by nitric oxide [114]. Coronary artery blood flow assessment after supine bicycle exercise is also feasible, correlating well with invasive measures [115], and has been used to demonstrate, in a randomised double-blinded crossover trial, that hormone replacement therapy and high dose statins increase coronary artery blood flow in postmenopausal patients without CAD [116]. Thus, Ex-CMR may have a future role in research studies investigating CAD pathogenesis in low risk populations.

\section{Athletic heart disease}

Ex-CMR studies show promise in providing an additional tool to differentiate the athletic heart adaptation from cardiomyopathy, and for risk stratifying endurance athletes against RV arrhythmias. Ex-CMR to maximal intensity on 14 endurance athletes after a $150 \mathrm{~km}$ cycle race, showed that the acute RV dilatation and reduced RV ejection fraction (RVEF), previously demonstrated 
with endurance exercise, worsened during further exercise and was not the result of confounding post-race variables such as increased afterload and autonomic activation [75]. Using Ex-CMR, endurance athletes with RV arrhythmias demonstrated more RV dysfunction during exercise, despite normal resting RV function, than athletes without RV arrhythmias and healthy controls [65]. In terms of differentiating the athletic heart from cardiomyopathy, when 10 healthy endurance athletes were compared with 9 endurance athletes with subepicardial fibrosis and 5 patients with dilated cardiomyopathy, they demonstrated a significantly greater augmentation of LV ejection fraction (LVEF) during exercise of $14 \pm 3 \%$, compared with $4 \pm 3 \%$ and $5 \pm 6 \%$ respectively. The endurance athletes with subepicardial fibrosis had similar resting haemodynamics and exercise capacity to the healthy endurance athletes, suggesting that Ex-CMR may be helpful in differentiating healthy endurance athletes from those with fibrosis [63].

\section{Congenital heart disease}

CMR has significant benefits over alternative noninvasive imaging modalities for the assessment of congenital heart disease, especially for complex lesions and right heart pathologies. These benefits have been utilised with supine ergometer Ex-CMR to assess the physiological responses to exercise in a variety of conditions (Table 4).

Despite normal resting biventricular function, patients with prior atrial correction for transposition of the great arteries (TGA) demonstrated little or no increase in EF \& stroke volume (SV) on Ex-CMR compared with healthy controls. The abnormal RV response to exercise correlated with exercise intolerance in these patients [71]. A subsequent study comparing haemodynamic response between Ex-CMR and dobutamine stress CMR also demonstrated no increase in SV and EF with exercise in atrial-corrected TGA patients, but a significant increase of SV and EF in controls during exercise and both groups during dobutamine stress CMR. This study demonstrated the two stress techniques could not be used interchangeably in this cohort of patients and reaffirmed the abnormal exercise response in atrialcorrected TGA patients. The differences in stress response between dobutamine and exercise are likely due to the differing effects on pre and afterload and could be present in other cardiac disease processes. Therefore, the type of stressor must be taken into account when interpreting the different methods [67]. A subsequent Ex-CMR study demonstrated a divergent cardiac response during Ex-CMR between atrial corrected TGA and congenitally corrected TGA (CC-TGA) patients, demonstrating the need for caution in performing pooled analysis of systemic RV (s-RV) patients. At rest, atrial corrected TGA patients had significantly higher global circumferential strain but similar global longitudinal strain and s-RVEDVi and ejection fraction. CCTGA patients demonstrated more pronounced septal interstitial expansion. During Ex-CMR, atrial corrected TGA patients demonstrated deteriorating s-RVEDVi and RV SV during exercise compared with an unchanged sRVEDVi and augmented RV SV in CC-TGA patients [80].

Ex-CMR has been important in demonstrating causes of exercise intolerance in patients with Fontan circulation. Pedersen et al. investigated patients with total cavopulmonary connection (TCPC), a palliative Fontan type operation, using supine bicycle Ex-CMR. At rest blood flow was lower to the smaller left lung. During exercise the flow increased proportionally with systemic venous return, IVC flow doubled and SVC flow increased slightly. The ratio of flow distribution to the lungs was unchanged with exercise, contrary to earlier resting studies demonstrating preferential streaming of IVC flow into the left pulmonary artery (LPA) and SVC to the right pulmonary artery (RPA) $[122,123]$. The study concluded that pulmonary vascular resistance, rather than anastomosies geometry, was the major factor effecting exercise flow distribution and thus exercises intolerance [98]. This assertion was further demonstrated in an ExCMR study in 10 Fontan patients, in which rest and exercise systemic volumes were assessed with simultaneous invasive radial artery and pulmonary artery pressure measurements before and after sildenafil. Sildenafil improved cardiac index during exercise with a decrease in total pulmonary resistance index and an increase in stroke volume index [78]. The 'respiratory pump' theorized in the Fontan circulation has been demonstrated in 10 Fontan patients who showed increased ventricular filling during inspiration which persisted during ExCMR. This may provide a rationale for respiratory muscle training in this patient group [79]. Subsequently, Wei et al. studied the significance of varying respiratory effects on flow in the TCPC anatomy by using real time phase contrast imaging to assess the SVC, IVC, ascending and descending aortic flow during breath holding, free breathing and exercise conditions. The study demonstrated that whilst respiration affects IVC and SVC waveform, it did not significantly affect mean flow. The study therefore validated using breath held images, which benefit from reduced image artefacts, for routine mean flow assessment in TCPC anatomy patients. Additionally, the study demonstrated interchangeable mean flows between the IVC and descending aorta, justifying the use of descending aorta flow as a surrogate for IVC flow, which is difficult to assess during exercise due to diaphragmatic motion, in TCPC anatomy patients [97]. Khiabani et al. demonstrated the association of exercise 
Table 4 Supine ergometer exercise CMR studies in Congenital Heart Disease

\begin{tabular}{|c|c|c|c|c|}
\hline Study & $\mathrm{n}$. & Population & Variable assessed & $\begin{array}{l}\text { Exercise } \\
\text { intensity* }\end{array}$ \\
\hline $\begin{array}{l}\text { Pedersen } \\
\text { (2002) [98] }\end{array}$ & 11 & $\begin{array}{l}\text { Children with } \\
\text { prior TCPC } \\
\text { operation }\end{array}$ & $\begin{array}{l}\text { SVC, IVC tunnel, LPA \& } \\
\text { RPA flow }\end{array}$ & $\begin{array}{l}\text { Low- } \\
\text { Moderate }\end{array}$ \\
\hline $\begin{array}{l}\text { Roest (2002) } \\
\text { [117] }\end{array}$ & 31 & $\begin{array}{l}\text { Repaired ToF (15) } \\
\text { \& healthy } \\
\text { volunteers (16) }\end{array}$ & $\begin{array}{l}\text { Biventricular volume and } \\
\text { pulmonary flow }\end{array}$ & Moderate \\
\hline $\begin{array}{l}\text { Roest (2004) } \\
\text { [71] }\end{array}$ & 41 & $\begin{array}{l}\text { Atrial corrected- } \\
\text { TGA (27), Healthy } \\
\text { control (14) }\end{array}$ & Biventricular volumes & Moderate \\
\hline $\begin{array}{l}\text { Oosterhof } \\
\text { (2005) [67] }\end{array}$ & 64 & $\begin{array}{l}\text { Atrial corrected } \\
\text { TGA (39) \& } \\
\text { Healthy } \\
\text { volunteers (25) }\end{array}$ & $\begin{array}{l}\text { Aortic flow and systemic } \\
\text { ventricle function } \\
\text { (exercise vs dobutamine } \\
\text { stress) }\end{array}$ & Vigorous \\
\hline
\end{tabular}

Lurz (2012) 17 PPVI for PR/PS as Biventricular volumes [118]

Van De

Bruaene

(2014) [78]

$\begin{array}{lrl}\begin{array}{l}\text { Van De } \\ \text { Bruaene } \\ \text { (2015) [79] }\end{array} & 10 & \begin{array}{l}\text { Fontan } \\ \text { circulation (10) }\end{array} \\ \begin{array}{l}\text { Khiabani } \\ \text { (2015) [119] }\end{array} & \begin{array}{l}\text { Fontan } \\ \text { circulation }\end{array}\end{array}$

Barber (2016) 30 Pediatric: [85]

Wei (2016)

[97]

11 Fontan circulation/TCPC

MR-CPEX

Systemic ventricle volumes, invasive radial and PA pressures

Systemic ventricle volumes, invasive radial and PA pressures

Ascending and descending aortic flow and SVC flow

Moderate/ to VAT

Until exhaustion pre-PPV|**

Realtime radial Ksense volumes

Submaximal Un-gated real time, freebreathing.

Submaximal 
Table 4 Supine ergometer exercise CMR studies in Congenital Heart Disease (Continued)

\begin{tabular}{|c|c|c|c|c|c|c|}
\hline Study & n. & Population & Variable assessed & $\begin{array}{l}\text { Exercise } \\
\text { intensity* }\end{array}$ & $\begin{array}{l}\text { Imaging } \\
\text { Technique }\end{array}$ & Findings \\
\hline [100] & & Control (34) & $\begin{array}{l}\text { Aortic and pulmonary } \\
\text { flow }\end{array}$ & & & $\begin{array}{l}\text { contractile reserve with exercise and healthy } \\
\text { controls had a reduced contractile reserve } \\
\text { exercising during hypoxia (breathing 12\% } \\
\text { oxygen) }\end{array}$ \\
\hline $\begin{array}{l}\text { Claessen } \\
\text { (2019) [77] }\end{array}$ & 30 & $\begin{array}{l}\text { Fontan (10), } \\
\text { Control (20) }\end{array}$ & $\begin{array}{l}\text { Systemic ventricle } \\
\text { volumes, invasive radial } \\
\text { and PA pressures }\end{array}$ & Maximal & & $\begin{array}{l}\text { Fontan patients have a diminished heart rate } \\
\text { reserve as a result of abnormal cardiac filling } \\
\text { rather than sinus atrial node dysfunction causing } \\
\text { chronotropic incompetence. }\end{array}$ \\
\hline
\end{tabular}

*Exercise intensities according to American college of sports medicine guidelines

**Patients exercised until exhaustion pre-PPVI, then post-PPVI patients exercised to the same exercise intensity as pre-PPVI

Abbreviations: CC congenitally corrected, $B H$ breath hold, FB free breathing, $i-P A H$ idiopathic pulmonary hypertension, IVC inferior vena cava, $L P A$ left pulmonary artery, RPA right pulmonary artery, SVC superior vena cava, TGA transposition of the great arteries, ToF tetralogy of Fallot, VAT ventillatory anaerobic threshold, VSD ventricular septal defect

performance with power loss in TCPC anatomies when performing an Ex-CMR study in 30 patients with Fontan circulation. Power loss calculations made from computational fluid dynamic simulations were performed on the in vivo TCPC anatomies and acquired flows, demonstrating that as cardiac output increased during exercise, power loss increased exponentially [119]. A subsequent Ex-CMR study demonstrated an inverse correlation between the TCPC diameter index, which accounts for vessel narrowing in the TCPC, and indexed power loss during Ex-CMR to the ventillatory anaerobic threshold, thus suggesting that reducing vessel narrowing and elevated power loss could improve exercise capacity and quality of life in patients with TCPC [120]. The diminished heart rate reserve often seen in Fontan patients was investigated in a recent Ex-CMR study and demonstrated as a likely secondary phenomenon rather than due to sinus atrial node dysfunction. 10 Fontan patients demonstrated an increased chronotropic response to exercise but an early plateau in cardiac output, compared with 20 healthy controls, caused by premature reductions in ventricular filling and stroke volume. This ExCMR study thus determined that the diminished heart rate reserve observed in Fontan patients was a result of abnormal cardiac filling rather than sinus atrial node dysfunction causing chronotropic incompetence [77].

Patients with prior surgically repaired VSD commonly have reduced functional capacity and often demonstrate resting retrograde ascending aortic flow. A recent ExCMR study demonstrated a decreased cardiac index in young adults exercised to submaximal intensity. This was determined secondary to a previously unrecognised increase in retrograde pulmonary flow with exercise along with previously demonstrated chronotropic incompetence in this patient group [61].

Ex-CMR has been demonstrated as feasible in repaired ToF in both adults [121] and children [85]. The seminal Ex-CMR study in repaired ToF patients by Roest et al. demonstrated an abnormal RV response to exercise compared with controls, but a decrease in pulmonary regurgitation [117]. A more recent study demonstrated reduced biventricular contractile reserve and aortic distensibility in repaired ToF patients compared to healthy subjects during Ex-CMR, which may be an early sign of increased aortic rigidity [121].

An Ex-CMR study assessing the exercise biventricular response to percutaneous pulmonary valve implantation (PPVI) in patients with either pulmonary regurgitation or pulmonary stenosis of heterogenous congenital aetiologies, demonstrated that PPVI resulted in restoration of RVEF exercise reserves in pulmonary stenosis patients but only a mild augmentation of exercise SV post PPVI in pulmonary regurgitation patients [118].

\section{Pulmonary hypertension}

Idiopathic PAH patients have shown worsened RV function and a failure to augment bi-ventricular stroke volumes during Ex-CMR when compared with healthy subjects [64]. A recent study found similar differences between healthy controls and PAH patients, but additionally, when healthy controls were exercised during hypoxia (breathing 12\% oxygen), which is associated with transient acute pulmonary hypertension, this resulted in decreased RV contractile reserve, but not as dramatically as PAH patients exercising during normoxia [100]. A further increase in pulmonary artery pressure during exercise in idiopathic PAH patients is the presumed cause of worsened RV contractile reserve; this was demonstrated in an Ex-CMR study of 15 patients with chronic thromboembolic pulmonary hypertension (CTEPH), 7 patients post pulmonary endartectomy (PEA) and 14 healthy controls. Despite a normal resting RVEF and mean pulmonary artery pressure post PEA, the RVEF and pulmonary compliance decreased with exercise in the post-PEA group along the CTEPH group. This was in contrast to healthy subjects 
whose RVEF increased with exercise and pulmonary compliance only mildly decreased. Treatment with sildenafil in the post-PEA group did not alter resting RVEF or haemodynamics, but significantly decreased exercise mean pulmonary artery pressure and increased exercise RVEF. Thus this Ex-CMR study demonstrated that postPEA patients display an abnormal pulmonary vascular reserve which can be partially reversed by Sildenafil [76].

\section{Diabetes}

Ex-CMR studies in diabetes mellitus have demonstrated that adolescents with type 1 diabetes mellitus (T1DM) have a reduced exercise capacity, and resting and exercise LV stroke volumes (which correlated to glycaemic control), compared with non-diabetic controls [88]. The same group demonstrated improved, but not normalised, LVEF in T1DM adolescents who undertook regular intense exercise for 20 weeks when compared with nonexercising T1DM controls, suggesting that the diastolic dysfunction could be partially reversed by regular intense exercise [89]. Impaired cardiac function during exercise was similarly demonstrated in adolescent type 2 diabetes mellitus (T2DM) patients when compared with obese non-diabetics and controls [81]. Similar to the studies in T1DM, the T2DM adolescents demonstrated smaller LV SV, EDV and ESV at rest and during exercise, with a smaller increase in EF than non-diabetic controls. As such, all 3 studies demonstrated a decreased cardiac reserve during exercise in adolescent diabetics, whether T1DM or T2DM, when compared with nondiabetic controls [81, 88, 89].

\section{Valve disease}

Ex-CMR studies in aortic regurgitation (AR) have demonstrated that isolated AR in children and adults decreased during 'steady state submaximal exercise' CMR, which equated to prolonged light in-scanner exercise on a custom built device [124]. Roberts et al. assessed the short term effects metoprolol and losartan had on exercise haemodynamics in chronic AR patients after supine exercise in a cross-over study, showing that with metoprolol there was a lower heart rate, greater AR regurgitant fraction, lower aortic distensibility and greater indexed LV EDV and ESV compared to Ex-CMR on losartan [125].

\section{Exercise CMR spectroscopy}

Phosphorus CMRS $\left({ }^{31} \mathrm{P}\right.$-CMRS) is a non-invasive means of assessing the myocardial phosphocreatine to adenosine triphosphate (ATP) concentration ratio (PCr/ATP) and a sensitive indicator of myocardial energy status. Numerous exercise ${ }^{31} \mathrm{P}$-CMRS studies have been performed. As minimal movement is essential, the majority of studies have employed IHG or prone exercise.
Although the feasibility of supine cycle ergometer exercise ${ }^{31} \mathrm{P}$-CMRS was demonstrated in healthy subjects in 1994, this technique has not since progressed to assessment of cardiac disease [126].

\section{Isometric hand grip ${ }^{31} \mathrm{P}-\mathrm{CMRS}$}

Weiss et al. performed the initial study in exercise CMRS, developing the ${ }^{31} \mathrm{P}$ CMRS stress test by performing CMRS before, during and after isometric hand grip exercise in patients with CAD, non-ischaemic heart disease and healthy controls. The study demonstrated a deceased regional $\mathrm{PCr} / \mathrm{ATP}$ ratio during exercise in patients with $>70 \%$ stenosis in the left anterior descending coronary artery (LAD) or left main coronary artery vs no change in healthy controls and patients with nonischaemic heart disease. The decreased PCr/ATP ratio improved 2 min after cessation of exercise and did not recur in those that had subsequent revascularization [105]. The technique was further validated by Yabe et al. as a sensitive method to detect myocardial ischaemia in those with reversible defects on ${ }^{201} \mathrm{~T} 1$ MPS-SPECT [127] and subsequently used to demonstrate decreased $\mathrm{PCr} / \mathrm{ATP}$ ratios on exercise in cardiac transplant patients [128] and patients with Chagas heart disease [129].

\section{Prone exercise ${ }^{31} \mathrm{P}$-CMRS}

Prone exercise ${ }^{31} \mathrm{P}$-CMRS has been used to investigate patients with T2DM and separately patients with hypertrophic cardiomyopathy (HCM). Resting ${ }^{31} \mathrm{P}$-CMRS studies have demonstrated decreased energy metabolism via a decreased PCr/ATP ratio in T2DM patients with functionally normal hearts [130]. A study by Levelt et al., employed prone knee flexion exercise stress to perform ${ }^{31} \mathrm{P}$-CMRS and an adenosine stress CMR to assess myocardial perfusion and oxygenation. The T2DM patients demonstrated a lower resting PCr/ATP ratio which decreased further with exercise compared to controls and a decrease in myocardial perfusion and oxygenation. The correlation between exercise myocardial perfusion and oxygenation and $\mathrm{PCr} / \mathrm{ATP}$ ratio at exercise suggested that coronary microvascular dysfunction exacerbated the cardiac energetics during exercise [109].

Dass et al. used prone knee flexion exercise stress to perform ${ }^{31} \mathrm{P}$-CMRS and an adenosine stress CMR to assess myocardial perfusion and peak filling rates in patients with HCM and healthy controls. The HCM patients demonstrated a lower resting $\mathrm{PCr} / \mathrm{ATP}$ ratio which decreased further with exercise compared to controls, a decrease in peak filling rates with exercise but no change in myocardial perfusion. PCr/ATP ratio and peak filling rates correlated strongly at rest and exercise in the HCM group, suggesting that abnormal cardiac energetics in HCM patients is a key mediator of exercise 
induced diastolic dysfunction commonly seen in this disease [108].

\section{Comparing Ex-CMR methods}

Within this review, all types of available/ previously studied Ex-CMR methodologies have been presented, with each having benefits and weaknesses as displayed in Table 1. To date, treadmill Ex-CMR has demonstrated the most clinical utility, with the multicentre EXACT trial, demonstrating excellent diagnostic value in $\mathrm{CAD}$ and superiority over exercise SPECT [45]. Additionally treadmill Ex-CMR is arguably the safest Ex-CMR technique to stress patients with suspected CAD, owing to exercise being performed with 12-lead ECG monitoring which is not feasible with in-scanner methods. Therefore currently, treadmill Ex-CMR is undoubtedly the first choice ExCMR method for diagnosing CAD and ischaemia assessment. Studies comparing treadmill Ex-CMR and pharmacological stress CMR, in the form of adenosine/ regadenoson stress perfusion or dobutamine stress cine CMR have not been performed. Treadmill Ex-CMR also benefits from simultaneously performing a Bruce protocol treadmill test, which provides additional prognostic and diagnostic information. However as demonstrated in Fig. 2, the average treadmill Ex-CMR test may take longer than pharmacological stress CMR and requires additional specialist equipment and technician training. In-scanner Ex-CMR, as discussed, allows for CMR imaging during multiple stages of continuous exercise. As such, supine bicycle Ex-CMR is best placed for investigating biventricular response and/or flow changes in non-CAD. With further developments, the ability to perform biventricular volume, aortic and pulmonary flow assessment during exercise will allow for accurate direct quantification of aortic and pulmonary artery flow and indirect assessment of mitral regurgitation and tricuspid regurgitation. Given resting CMR quantification of valvular regurgitant flow has demonstrated superior reproducibility and prognostic value over TTE [131-133] and an abnormal response during stress echocardiography can prompt intervention in asymptomatic valve disease [134], Ex-CMR could become an important clinical tool to assess valvular and congenital heart disease. However, commercially available CMR compatible supine cycle ergometers are expensive, therefore institutions wishing to perform Ex-CMR research, in which achieving maximal heart rates are not required, may opt to create a custom device or utilise cheaper alternatives such as prone exercise with ankle weights or resistance bands, indeed isometric hand grip may be preferable for performing exercise CMRS as it produces minimal movement artefact and the modest heart rate increases achieved are sufficient to detect changes in numerous cardiac diseases.

\section{Future of Ex-CMR}

The potential clinical applications for Ex-CMR are considerable, however further technological developments and multicentre trials are needed to demonstrate the clinical utility of Ex-CMR. Ex-CMR will likely dichotomise into treadmill Ex-CMR as an investigation for CAD, and inscanner Ex-CMR for non-CAD indications, owing to the safer monitoring treadmill Ex-CMR offers and the ability to assess biventricular volumes at numerous exercise stages with in-scanner Ex-CMR. The recently completed multi-centre EXACT-COST trial, if favourable, may assist treadmill Ex-CMR gaining greater clinical use in CAD diagnosis and assessment. In-scanner Ex-CMR could benefit from new faster imaging techniques, to further reduce scanning and exercise time, to take full advantage of the multiparametric benefits CMR offers. Development of imaging techniques which allow volume and flow assessment during continuous exercise that can be analysed in a timely fashion on commercially available software is another important need to increase attainability. 4D flow has recently emerged as a valuable research tool [135]. Its use in Ex-CMR has recently been presented in abstract form demonstrating inefficient right heart function in preterm adults [136]. If feasible and reproducible during continuous exercise it could allow for a comprehensive volumetric and flow assessment during exercise. Clearly further research is needed with such emerging techniques to further enhance the capabilities of Ex-CMR, but with further technological advances Ex-CMR could potentially revolutionise stress CMR.

\section{Conclusion}

Ex-CMR offers the potential to combine the superior imaging quality of CMR with the preferred and physiological method of stress by exercise. Numerous exercise options exist, including CMR scanner adjacent treadmills or in-scanner exercise with a supine cycle ergometer or stepper, prone exercise or IHG exercises. Imaging during maximal intensity in-scanner exercise is feasible using a supine cycle ergometer with ungated real-time imaging. Further advances are required to improve acquisition techniques and decrease scan time, to allow for a comprehensive multi-parametric assessment during exercise, which if feasible could revolutionise stress CMR.

\section{Supplementary information}

Supplementary information accompanies this paper at https://doi.org/10. 1186/s12968-020-00652-w.

Additional file 1 Video 1. Transfer from CMR compatible treadmill to CMR scanner. Example of the transfer process from a CMR adjacent treadmill to the CMR scanner for post stress imaging, as performed by the Ohio State University research group [27].

Additional file $\mathbf{2}$ Video 2 . In-scanner supine cycle ergometer exercise and resulting cine images by un-gated real time cine imaging. Example 
of the use of the supine cycle ergometer for in-scanner exercise. Video with corresponding cine imaging in the short axis and 4-chamber horizontal long axis from un-gated real time imaging provided by La Gerche et al. [29].

\section{Abbreviations}

AR: Aortic regurgitation; ATP: Adenosine Triphosphate; $\mathrm{BH}$ : Breath hold: BPM: Beats per minute; bSSFP: Balanced steady state free precision; CAD: Coronary artery disease; CC-TGA: Congenitally corrected transposition of the great arteries; CMR: Cardiovascular magnetic resonance; CMRS: Cardiovascular magnetic resonance spectroscopy; CPET: Cardiopulmonary exercise test; CTEPH: Chronic thromboembolic pulmonary hypertension; ECG: Electrocardiogram; EDV: End-diastolic volume; EF: Ejection fraction; EPI: Echo planar imaging; ESV: End systolic volume; ExCMR: Exercise cardiovascular magnetic resonance; FB: Free breathing; GRAPPA: Generalized auto-calibrating partially parallel acquisition; HCM: Hypertrophic cardiomyopathy; HRmax: Maximal heart rate; IHG: Isometric hand grip; i-PAH: Idiopathic pulmonary artery hypertension; IPAT: Integrated parallel imaging; IVC: Inferior vena cava; LPA: Left pulmonary artery; LV: Left ventricle/left ventricular; LVEF: Left ventricular ejection fraction; LVSV: Left ventricular stroke volume; MPS-SPECT: Myocardial perfusion scintigraphy by single photon emission computed tomography; MRCPET: Magnetic resonance cardiopulmonary exercise testing; MVr: Mitral valve repair; MVR: Mitral valve replacement; NYHA: New York Heart Association; PAH: Pulmonary arterial hypertension; PCMRS: Phosphorus cardiodiovascular magnetic resonance spectroscopy; PCr: Phosphocreatinine; PEA: Pulmonary endartectomy; PPVI: Percutaneous pulmonary valve implantation; RPA: Right pulmonary artery; RV: Right ventricle/right ventricular; RVEF: Right ventricular ejection fraction; RVSV: Right ventricular stroke volume; s-RV: Systemic right ventricle; SENSE: Sensitivity encoding; SV: Stroke volume; SVC: Superior vena cava; T : Tesla; T1DM: Type 1 diabetes mellitus; T2DM: Type 2 diabetes mellitus; TCPC: Total cavo-pulmonary connection; TGA: Transposition of the great arteries; THR: Target heart rate; ToF: Tetralogy of Fallot; TTE: Transthoracic echocardiography; VO2 max: Maximal oxygen consumption; VSD: Ventricular septal defect

\section{Acknowledgements}

\section{Not applicable.}

\section{Authors' contributions}

TPC led the design, performed literature search and drafted the manuscript. $\mathrm{CT}, \mathrm{AG}, \mathrm{OS} \& \mathrm{JPG}$ reviewed and revised the manuscript; whilst JPG contributed to the conception, offered intellectual input and approved the final version of manuscript.

\section{Funding}

This literature review has no specific funding. Connie Tsao funding details: $\mathrm{NIH}$ R03HL145195. Orlando Simonetti has research grants (through his institution) from Siemens Healthineers and Myocardial Solutions. All remaining co-authors have no funding to disclose.

\section{Availability of data and materials}

All literature reviewed is attainable by online search using PubMed or Google Scholar. The only abstract presented in this review is located on the individual journals website.

\section{Ethics approval and consent to participate} Not applicable.

\section{Consent for publication}

All people involved in the images and videos have provided informed consent to publication.

\section{Competing interests}

\section{Not applicable.}

\section{Author details}

${ }^{1}$ Leeds Institute of Cardiovascular and Metabolic Medicine, University of Leeds, Leeds, UK. ${ }^{2}$ Cardiovascular Division, Beth Israel Deaconess Medical Center, 330 Brookline Ave, RW-453, Boston, MA 02215, USA. ${ }^{3}$ Clinical
Research Domain, Baker Heart and Diabetes Institute, Melbourne, Australia. ${ }^{4}$ National Centre for Sports Cardiology, St Vincent's Hospital, Fitzroy, Australia. ${ }^{5}$ The Ohio State University, Columbus, OH, USA.

Received: 18 September 2019 Accepted: 1 July 2020

Published online: 10 September 2020

\section{References}

1. Gibbons RJ, Balady GJ, Beasley JW, Bricker JT, Duvernoy WF, Froelicher VF, et al. ACC/AHA guidelines for exercise testing: executive summary. A report of the American College of Cardiology/American Heart Association Task Force on practice guidelines (committee on exercise testing). Circulation. 1997:96(1):345-54.

2. Bruce RA, Blackmon JR, Jones JW, Strait G. Exercising Testing in Adult Normal Subjects and Cardiac Patients. Pediatrics. 1963;32(SUPPL):742-56.

3. Bailey IK, Griffith LS, Rouleau J, Strauss W, Pitt B. Thallium-201 myocardial perfusion imaging at rest and during exercise. Comparative sensitivity to electrocardiography in coronary artery disease. Circulation. 1977;55(1):79-87.

4. Bokhari S, Shahzad A, Bergmann SR. Superiority of exercise myocardial perfusion imaging compared with the exercise ECG in the diagnosis of coronary artery disease. Coron Artery Dis. 2008;19(6):399-404.

5. Armstrong WF, O'Donnell J, Dillon JC, McHenry PL, Morris SN, Feigenbaum $\mathrm{H}$. Complementary value of two-dimensional exercise echocardiography to routine treadmill exercise testing. Ann Intern Med. 1986;105(6):829-35.

6. Banerjee A, Newman DR, Van den Bruel A, Heneghan C. Diagnostic accuracy of exercise stress testing for coronary artery disease: a systematic review and meta-analysis of prospective studies. Int J Clin Pract. 2012;66(5): 477-92.

7. Jeetley P, Burden L, Senior R. Stress echocardiography is superior to exercise ECG in the risk stratification of patients presenting with acute chest pain with negative troponin. Eur J Echocardiogr. 2006;7(2):155-64.

8. Kafka H, Leach AJ, Fitzgibbon GM. Exercise echocardiography after coronary artery bypass surgery: correlation with coronary angiography. J Am Coll Cardiol. 1995;25(5):1019-23.

9. Task Force M, Montalescot G, Sechtem U, Achenbach S, Andreotti F, Arden C, et al. 2013 ESC guidelines on the management of stable coronary artery disease: the Task Force on the management of stable coronary artery disease of the European Society of Cardiology. Eur Heart J. 2013;34(38): 2949-3003.

10. Knuuti J, Wijns W, Saraste A, Capodanno D, Barbato E, Funck-Brentano C, et al. 2019 ESC guidelines for the diagnosis and management of chronic coronary syndromes. Eur Heart J. 2020;41(3):407-77.

11. Lopez-Mattei JC, Shah DJ. The role of cardiac magnetic resonance in valvular heart disease. Methodist Debakey Cardiovasc J. 2013;9(3):142-8.

12. Gulsin GS, Singh A, McCann GP. Cardiovascular magnetic resonance in the evaluation of heart valve disease. BMC Med Imaging. 2017;17(1):67.

13. Bellenger NG, Burgess MI, Ray SG, Lahiri A, Coats AJ, Cleland JG, et al. Comparison of left ventricular ejection fraction and volumes in heart failure by echocardiography, radionuclide ventriculography and cardiovascular magnetic resonance; are they interchangeable? Eur Heart J. 2000;21(16):1387-96.

14. Greenwood JP, Maredia N, Younger JF, Brown JM, Nixon J, Everett CC, et al. Cardiovascular magnetic resonance and single-photon emission computed tomography for diagnosis of coronary heart disease (CE-MARC): a prospective trial. Lancet. 2012;379(9814):453-60.

15. Greenwood JP, Maredia N, Radjenovic A, Brown JM, Nixon J, Farrin AJ, et al. Clinical evaluation of magnetic resonance imaging in coronary heart disease: the CE-MARC study. Trials. 2009;10:62.

16. Greenwood JP, Herzog BA, Brown JM, Everett CC, Nixon J, Bijsterveld P, et al. Prognostic value of cardiovascular magnetic resonance and singlephoton emission computed tomography in suspected coronary heart disease: long-term follow-up of a prospective, diagnostic accuracy cohort study. Ann Intern Med. 2016;165(1):1-9.

17. Nagel E, Greenwood JP, McCann GP, Bettencourt N, Shah AM, Hussain ST, et al. Magnetic resonance perfusion or fractional flow Reserve in Coronary Disease. N Engl J Med. 2019;380(25):2418-28.

18. Lancellotti P, Pellikka PA, Budts W, Chaudhry FA, Donal E, Dulgheru R, et al. The clinical use of stress echocardiography in non-Ischaemic heart disease: recommendations from the European Association of Cardiovascular Imaging and the American Society of Echocardiography. J Am Soc Echocardiogr. 2017;30(2):101-38. 
19. Varga A, Garcia MA, Picano E. International stress Echo complication R. safety of stress echocardiography (from the international stress Echo complication registry). Am J Cardiol. 2006;98(4):541-3.

20. Kramer CM, Barkhausen J, Flamm SD, Kim RJ, Nagel E. Society for Cardiovascular Magnetic Resonance Board of Trustees Task Force on Standardized P. Standardized cardiovascular magnetic resonance (CMR) protocols 2013 update. J Cardiovasc Magn Reson. 2013;15:91.

21. Pellikka PA, Nagueh SF, Elhendy AA, Kuehl CA, Sawada SG. American Society of E. American Society of Echocardiography recommendations for performance, interpretation, and application of stress echocardiography. J Am Soc Echocardiogr. 2007;20(9):1021-41

22. Wolk MJ, Bailey SR, Doherty JU, Douglas PS, Hendel RC, Kramer CM, et al. ACCF/AHA/ASE/ASNC/HFSA/HRS/SCAI/SCCT/SCMR/STS 2013 multimodality appropriate use criteria for the detection and risk assessment of stable ischemic heart disease: a report of the American College of Cardiology Foundation Appropriate Use Criteria Task Force, American Heart Association, American Society of Echocardiography, American Society of Nuclear Cardiology, Heart Failure Society of America, Heart Rhythm Society, Society for Cardiovascular Angiography and Interventions, Society of Cardiovascular Computed Tomography, Society for Cardiovascular Magnetic Resonance, and Society of Thoracic Surgeons. J Am Coll Cardiol. 2014;63(4):380-406.

23. Nishimura RA, Otto CM, Bonow RO, Carabello BA, Erwin JP 3rd, Guyton RA, et al. 2014 AHA/ACC guideline for the management of patients with valvular heart disease: a report of the American College of Cardiology/ American Heart Association Task Force on practice guidelines. J Thorac Cardiovasc Surg. 2014;148(1):e1-e132.

24. Stout KK, Daniels CJ, Aboulhosn JA, Bozkurt B, Broberg CS, Colman JM, et al. 2018 AHA/ACC guideline for the Management of Adults with Congenital Heart Disease: executive summary: a report of the American College of Cardiology/American Heart Association Task Force on clinical practice guidelines. J Am Coll Cardiol. 2019;73(12):1494-563.

25. Gusso S, Salvador C, Hofman P, Cutfield W, Baldi JC, Taberner A, et al. Design and testing of an MRI-compatible cycle ergometer for non-invasive cardiac assessments during exercise. Biomed Eng Online. 2012;11:13.

26. Sicari R, Nihoyannopoulos P, Evangelista A, Kasprzak J, Lancellotti P, Poldermans D, et al. Stress echocardiography expert consensus statement: European Association of Echocardiography (EAE) (a registered branch of the ESC). Eur J Echocardiogr. 2008;9(4):415-37.

27. Foster EL, Arnold JW, Jekic M, Bender JA, Balasubramanian V, Thavendiranathan $\mathrm{P}$, et al. MR-compatible treadmill for exercise stress cardiac magnetic resonance imaging. Magn Reson Med. 2012;67(3):880-9.

28. Expert Panel on MRS, Kanal E, Barkovich AJ, Bell C, Borgstede JP, Bradley WG Jr, et al. ACR guidance document on MR safe practices: 2013. J Magn Reson Imaging. 2013;37(3):501-30.

29. La Gerche A, Claessen G, Van de Bruaene A, Pattyn N, Van Cleemput J, Gewillig M, et al. Cardiac MRl: a new gold standard for ventricular volume quantification during high-intensity exercise. Circ Cardiovasc Imaging. 2013: 6(2):329-38

30. Fischer SE, Wickline SA, Lorenz $\mathrm{CH}$. Novel real-time R-wave detection algorithm based on the vectorcardiogram for accurate gated magnetic resonance acquisitions. Magn Reson Med. 1999;42(2):361-70.

31. Raman SV, Dickerson JA, Jekic M, Foster EL, Pennell ML, McCarthy B, et al. Real-time cine and myocardial perfusion with treadmill exercise stress cardiovascular magnetic resonance in patients referred for stress SPECT. J Cardiovasc Magn Reson. 2010;12:41.

32. Garber CE, Blissmer B, Deschenes MR, Franklin BA, Lamonte MJ, Lee IM, et al. American College of Sports Medicine position stand. Quantity and quality of exercise for developing and maintaining cardiorespiratory, musculoskeletal, and neuromotor fitness in apparently healthy adults: guidance for prescribing exercise. Med Sci Sports Exerc. 2011;43(7): 1334-59.

33. Rerkpattanapipat P, Gandhi SK, Darty SN, Williams RT, Davis AD, Mazur W, et al. Feasibility to detect severe coronary artery stenoses with upright treadmill exercise magnetic resonance imaging. Am J Cardiol. 2003;92(5):603-6.

34. Jekic M, Foster EL, Ballinger MR, Raman SV, Simonetti OP. Cardiac function and myocardial perfusion immediately following maximal treadmill exercise inside the MRI room. J Cardiovasc Magn Reson. 2008;10:3.

35. Hecht HS, DeBord L, Sotomayor N, Shaw R, Dunlap R, Ryan C. Supine bicycle stress echocardiography: peak exercise imaging is superior to postexercise imaging. J Am Soc Echocardiogr. 1993;6(3 Pt 1):265-71.
36. Presti CF, Armstrong WF, Feigenbaum H. Comparison of echocardiography at peak exercise and after bicycle exercise in evaluation of patients with known or suspected coronary artery disease. J Am Soc Echocardiogr. 1988;1(2):119-26.

37. Peteiro J, Garrido I, Monserrat L, Aldama G, Calvino R, Castro-Beiras A. Comparison of peak and postexercise treadmill echocardiography with the use of continuous harmonic imaging acquisition. J Am Soc Echocardiogr. 2004;17(10):1044-9.

38. Peteiro J, Fabregas R, Montserrat L, Alvarez N, Castro-Beiras A. Comparison of treadmill exercise echocardiography before and after exercise in the evaluation of patients with known or suspected coronary artery disease. J Am Soc Echocardiogr. 1999;12(12):1073-9.

39. Peteiro J, Monserrat L, Perez R, Vazquez E, Vazquez JM, Castro-Beiras A. Accuracy of peak treadmill exercise echocardiography to detect multivessel coronary artery disease: comparison with post-exercise echocardiography. Eur J Echocardiogr. 2003;4(3):182-90.

40. Peteiro J, Bouzas-Mosquera A, Broullon FJ, Garcia-Campos A, Pazos P, Castro-Beiras A. Prognostic value of peak and post-exercise treadmill exercise echocardiography in patients with known or suspected coronary artery disease. Eur Heart J. 2010;31(2):187-95.

41. Peteiro J, Bouzas-Mosquera A, Estevez R, Pazos P, Pineiro M, Castro-Beiras A. Head-to-head comparison of peak supine bicycle exercise echocardiography and treadmill exercise echocardiography at peak and at post-exercise for the detection of coronary artery disease. J Am Soc Echocardiogr. 2012;25(3):319-26.

42. Thavendiranathan P, Dickerson JA, Scandling D, Balasubramanian V, Pennell ML, Hinton A, et al. Comparison of treadmill exercise stress cardiac MRI to stress echocardiography in healthy volunteers for adequacy of left ventricular endocardial wall visualization: a pilot study. J Magn Reson Imaging. 2014;39(5):1146-52.

43. Sukpraphrute B, Drafts BC, Rerkpattanapipat P, Morgan TM, Kirkman PM, Ntim WO, et al. Prognostic utility of cardiovascular magnetic resonance upright maximal treadmill exercise testing. J Cardiovasc Magn Reson. 2015;17:103.

44. Lafountain RA, da Silveira JS, Varghese J, Mihai G, Scandling D, Craft J, et al. Cardiopulmonary exercise testing in the MRI environment. Physiol Meas. 2016;37(4):N11-25

45. Raman SV, Dickerson JA, Mazur W, Wong TC, Schelbert EB, Min JK, et al. Diagnostic Performance of Treadmill Exercise Cardiac Magnetic Resonance: The Prospective, Multicenter Exercise CMR's Accuracy for Cardiovascular Stress Testing (EXACT) Trial. J Am Heart Assoc. 2016;5(8):e003811.

46. Korosoglou G, Giusca S, Gitsioudis G, Erbel C, Katus HA. Cardiac magnetic resonance and computed tomography angiography for clinical imaging of stable coronary artery disease. Diagnostic classification and risk stratification. Front Physiol. 2014;5:291.

47. Gosselink R, Troosters T, Decramer M. Exercise testing: why, which and how to interpret. Breathe. 2004;1(2):120-9.

48. Badruddin SM, Ahmad A, Mickelson J, Abukhalil J, Winters WL, Nagueh SF, et al. Supine bicycle versus post-treadmill exercise echocardiography in the detection of myocardial ischemia: a randomized single-blind crossover trial. J Am Coll Cardiol. 1999;33(6):1485-90.

49. Ashley EA, Myers J, Froelicher V. Exercise testing in clinical medicine. Lancet. 2000;356(9241):1592-7.

50. Tavel ME, Shaar C. Relation between the electrocardiographic stress test and degree and location of myocardial ischemia. Am J Cardiol. 1999;84(2):119-24.

51. Kligfield P, Lauer MS. Exercise electrocardiogram testing: beyond the ST segment. Circulation. 2006;114(19):2070-82.

52. Jekic M, Ding Y, Dzwonczyk R, Burns P, Raman SV, Simonetti OP. Magnetic field threshold for accurate electrocardiography in the MRI environment. Magn Reson Med. 2010;64(6):1586-91.

53. Fletcher GF, Ades PA, Kligfield P, Arena R, Balady GJ, Bittner VA, et al. Exercise standards for testing and training: a scientific statement from the American Heart Association. Circulation. 2013;128(8):873-934.

54. Pflugi S, Roujol S, Akcakaya M, Kawaji K, Foppa M, Heydari B, et al. Accelerated cardiac MR stress perfusion with radial sampling after physical exercise with an MR-compatible supine bicycle ergometer. Magn Reson Med. 2015;74(2):384-95.

55. Heiberg J, Asschenfeldt B, Maagaard M, Ringgaard S. Dynamic bicycle exercise to assess cardiac output at multiple exercise levels during magnetic resonance imaging. Clin Imaging. 2017;46:102-7.

56. Modesto KM, Rainbird A, Klarich KW, Mahoney DW, Chandrasekaran K, Pellikka PA. Comparison of supine bicycle exercise and treadmill exercise 
Doppler echocardiography in evaluation of patients with coronary artery disease. Am J Cardiol. 2003:91(10):1245-8.

57. Wicks JR, Sutton JR, Oldridge NB, Jones NL. Comparison of the electrocardiographic changes induced by maximam exercise testing with treadmill and cycle ergometer. Circulation. 1978;57(6):1066-70.

58. Quinn TJ, Smith SW, Vroman NB, Kertzer R, Olney WB. Physiologic responses of cardiac patients to supine, recumbent, and upright cycle ergometry. Arch Phys Med Rehabil. 1995;76(3):257-61.

59. Mohiaddin RH, Gatehouse PD, Firmin DN. Exercise-related changes in aortic flow measured with spiral echo-planar MR velocity mapping. J Magn Reson Imaging. 1995;5(2):159-63.

60. Niezen RA, Doornbos J, van der Wall EE, de Roos A. Measurement of aortic and pulmonary flow with MRI at rest and during physical exercise. J Comput Assist Tomogr. 1998;22(2):194-201.

61. Asschenfeldt B, Heiberg J, Ringgaard S, Maagaard M, Redington A, Hjortdal VE. Impaired cardiac output during exercise in adults operated for ventricular septal defect in childhood: a hitherto unrecognised pathophysiological response. Cardiol Young. 2017;27(8):1591-8.

62. Claessen G, Claus P, Delcroix M, Bogaert J, La Gerche A, Heidbuchel H. Interaction between respiration and right versus left ventricular volumes at rest and during exercise: a real-time cardiac magnetic resonance study. Am J Physiol Heart Circ Physiol. 2014;306(6):H816-24.

63. Claessen G, Schnell F, Bogaert J, Claeys M, Pattyn N, De Buck F, et al, Exercise cardiac magnetic resonance to differentiate athlete's heart from structural heart disease. Eur Heart J Cardiovasc Imaging. 2018;19(9):1062-70.

64. Holverda S, Gan CT, Marcus JT, Postmus PE, Boonstra A, Vonk-Noordegraaf A. Impaired stroke volume response to exercise in pulmonary arterial hypertension. J Am Coll Cardiol. 2006;47(8):1732-3.

65. La Gerche A, Claessen G, Dymarkowski S, Voigt JU, De Buck F, Vanhees $L$, et al. Exercise-induced right ventricular dysfunction is associated with ventricular arrhythmias in endurance athletes. Eur Heart J. 2015;36(30): 1998-2010.

66. Le TT, Bryant JA, Ting AE, Ho PY, Su B, Teo RC, et al. Assessing exercise cardiac reserve using real-time cardiovascular magnetic resonance. Cardiovasc Magn Reson. 2017;19(1):7.

67. Oosterhof T, Tulevski II, Roest AA, Steendijk P, Vliegen HW, van der Wall $\mathrm{EE}$, et al. Disparity between dobutamine stress and physical exercise magnetic resonance imaging in patients with an intra-atrial correction for transposition of the great arteries. J Cardiovasc Magn Reson. 2005; 7(2):383-9.

68. Pedersen EM, Kozerke S, Ringgaard S, Scheidegger MB, Boesiger P. Quantitative abdominal aortic flow measurements at controlled levels of ergometer exercise. Magn Reson Imaging. 1999;17(4):489-94.

69. Pieles GE, Szantho G, Rodrigues JC, Lawton CB, Stuart AG, Bucciarelli-Ducci $C$, et al. Adaptations of aortic and pulmonary artery flow parameters measured by phase-contrast magnetic resonance angiography during supine aerobic exercise. Eur J Appl Physiol. 2014;114(5):1013-23.

70. Roest AA, Kunz P, Lamb HJ, Helbing WA, van der Wall EE, de Roos A. Biventricular response to supine physical exercise in young adults assessed with ultrafast magnetic resonance imaging. Am J Cardiol. 2001;87(5):601-5

71. Roest AA, Lamb HJ, van der Wall EE, Vliegen HW, van den Aardweg JG, Kunz $\mathrm{P}$, et al. Cardiovascular response to physical exercise in adult patients after atrial correction for transposition of the great arteries assessed with magnetic resonance imaging. Heart. 2004;90(6):678-84.

72. Sampath S, Derbyshire JA, Ledesma-Carbayo MJ, McVeigh ER. Imaging left ventricular tissue mechanics and hemodynamics during supine bicycle exercise using a combined tagging and phase-contrast MRI pulse sequence. Magn Reson Med. 2011;65(1):51-9.

73. Schnell F, Claessen G, La Gerche A, Claus P, Bogaert J, Delcroix M, et al. Atrial volume and function during exercise in health and disease. J Cardiovasc Magn Reson. 2017;19(1):104

74. Weber TF, von Tengg-Kobligk H, Kopp-Schneider A, Ley-Zaporozhan J, Kauczor HU, Ley S. High-resolution phase-contrast MRI of aortic and pulmonary blood flow during rest and physical exercise using a MR compatible bicycle ergometer. Eur J Radiol. 2011;80(1):103-8.

75. Claessen G, Claus P, Ghysels S, Vermeersch P, Dymarkowski S, LAG A, et al. Right ventricular fatigue developing during endurance exercise: an exercise cardiac magnetic resonance study. Med Sci Sports Exerc. 2014;46(9):1717-26.

76. Claessen G, La Gerche A, Dymarkowski S, Claus P, Delcroix M, Heidbuchel H. Pulmonary vascular and right ventricular reserve in patients with normalized resting hemodynamics after pulmonary endarterectomy. J Am Heart Assoc. 2015;4(3):e001602.

77. Claessen G, La Gerche A, Van De Bruaene A, Claeys M, Willems R, Dymarkowski $S$, et al. Heart rate Reserve in Fontan Patients: Chronotropic incompetence or hemodynamic limitation? J Am Heart Assoc. 2019;8(9):e012008.

78. Van De Bruaene A, La Gerche A, Claessen G, De Meester P, Devroe S, Gillijns $\mathrm{H}$, et al. Sildenafil improves exercise hemodynamics in Fontan patients. Circ Cardiovasc Imaging. 2014;7(2):265-73.

79. Van De Bruaene A, Claessen G, La Gerche A, Kung E, Marsden A, De Meester $P$, et al. Effect of respiration on cardiac filling at rest and during exercise in Fontan patients: a clinical and computational modeling study. Int J Cardiol Heart Vasculature. 2015;9:100-8.

80. Helsen F, Claus P, Van De Bruaene A, Claessen G, La Gerche A, De Meester $P$, et al. Advanced imaging to phenotype patients with a systemic right ventricle. J Am Heart Assoc. 2018;7(20):e009185.

81. Pinto TE, Gusso S, Hofman PL, Derraik JG, Hornung TS, Cutfield WS, et al. Systolic and diastolic abnormalities reduce the cardiac response to exercise in adolescents with type 2 diabetes. Diabetes Care. 2014;37(5):1439-46.

82. Steding-Ehrenborg K, Jablonowski R, Arvidsson PM, Carlsson M, Saltin B, Arheden $\mathrm{H}$. Moderate intensity supine exercise causes decreased cardiac volumes and increased outer volume variations: a cardiovascular magnetic resonance study. J Cardiovasc Magn Reson. 2013;15:96.

83. Lurz P, Muthurangu V, Schievano S, Nordmeyer J, Bonhoeffer P, Taylor AM, et al. Feasibility and reproducibility of biventricular volumetric assessment of cardiac function during exercise using real-time radial k-t SENSE magnetic resonance imaging. J Magn Reson Imaging. 2009;29(5):1062-70.

84. Barber NJ, Ako EO, Kowalik GT, Steeden JA, Pandya B, Muthurangu V. MR augmented cardiopulmonary exercise testing-a novel approach to assessing cardiovascular function. Physiol Meas. 2015;36(5):N85-94.

85. Barber NJ, Ako EO, Kowalik GT, Cheang MH, Pandya B, Steeden JA, et al. Magnetic Resonance-Augmented Cardiopulmonary Exercise Testing: Comprehensively Assessing Exercise Intolerance in Children With Cardiovascular Disease. Circ Cardiovasc Imaging. 2016;9(12):e005282.

86. Beaudry RI, Samuel TJ, Wang J, Tucker WJ, Haykowsky MJ, Nelson MD. Exercise cardiac magnetic resonance imaging: a feasibility study and metaanalysis. Am J Phys Regul Integr Comp Phys. 2018;315(4):R638-R45.

87. Forouzan O, Warczytowa J, Wieben O, Francois CJ, Chesler NC. Non-invasive measurement using cardiovascular magnetic resonance of changes in pulmonary artery stiffness with exercise. J Cardiovasc Magn Reson. 2015;17:109.

88. Gusso S, Pinto TE, Baldi JC, Robinson E, Cutfield WS, Hofman PL. Diastolic function is reduced in adolescents with type 1 diabetes in response to exercise. Diabetes Care. 2012;35(10):2089-94.

89. Gusso S, Pinto T, Baldi JC, Derraik JGB, Cutfield WS, Hornung T, et al. Exercise training improves but does not normalize left ventricular systolic and diastolic function in adolescents with type 1 diabetes. Diabetes Care. 2017:40(9):1264-72.

90. Enos JD, Xue H, Kellman P, Hansen M, Cross R. Free-Breathing Mri Evaluation of Cardiac Volume Measurements during in-Scanner Exercise. J Am Coll Cardiol. 2017:69(11):1455.

91. Poliner LR, Dehmer GJ, Lewis SE, Parkey RW, Blomqvist CG, Willerson JT. Left ventricular performance in normal subjects: a comparison of the responses to exercise in the upright and supine positions. Circulation. 1980;62(3):528-34.

92. Furukawa K, Nishida K, Yamada C, Niki S, Sugihara H, Kohno Y, et al. Left ventricular size and performance during graded supine exercise in normal subjects. Jpn Heart J. 1983:24(4):503-14.

93. Gorlin R, Cohen LS, Elliott WC, Klein MD, Lane FJ. Effect of supine exercise on left ventricular volume and oxygen consumption in man. Circulation. 1965;32(3):361-71.

94. Crawford $\mathrm{MH}$, White $\mathrm{DH}$, Amon KW. Echocardiographic evaluation of left ventricular size and performance during handgrip and supine and upright bicycle exercise. Circulation. 1979;59(6):1188-96.

95. Stein RA, Michielli D, Fox EL, Krasnow N. Continuous ventricular dimensions in man during supine exercise and recovery. An echocardiographic study. Am J Cardiol. 1978:41(4):655-60.

96. Wong DT, Lee KJ, Yoo SJ, Tomlinson G, Grosse-Wortmann L. Changes in systemic and pulmonary blood flow distribution in normal adult volunteers in response to posture and exercise: a phase contrast magnetic resonance imaging study. J Physiol Sci. 2014;64(2):105-12.

97. Wei Z, Whitehead KK, Khiabani RH, Tree M, Tang E, Paridon SM, et al. Respiratory effects on Fontan circulation during rest and exercise using real-time cardiac magnetic resonance imaging. Ann Thorac Surg. 2016;101(5):1818-25. 
98. Pedersen EM, Stenbog EV, Frund T, Houlind K, Kromann O, Sorensen KE, et al. Flow during exercise in the total cavopulmonary connection measured by magnetic resonance velocity mapping. Heart. 2002;87(6):554-8.

99. Steeden JA, Atkinson D, Taylor AM, Muthurangu V. Assessing vascular response to exercise using a combination of real-time spiral phase contrast MR and noninvasive blood pressure measurements. J Magn Reson Imaging. 2010;31(4):997-1003

100. Jaijee S, Quinlan M, Tokarczuk P, Clemence M, Howard L, Gibbs JSR, et al. Exercise cardiac MRI unmasks right ventricular dysfunction in acute hypoxia and chronic pulmonary arterial hypertension. Am J Physiol Heart Circ Physiol. 2018;315(4):H950-H7

101. Cheng CP, Herfkens RJ, Taylor CA, Feinstein JA. Proximal pulmonary artery blood flow characteristics in healthy subjects measured in an upright posture using MRI: the effects of exercise and age. J Magn Reson Imaging. 2005;21(6):752-8.

102. Simonetti OP, Ahmad R. Low-Field Cardiac Magnetic Resonance Imaging: A Compelling Case for Cardiac Magnetic Resonance's Future. Circ Cardiovasc Imaging. 2017;10(6):e005446.

103. Garg R, Malhotra V, Kumar A, Dhar U, Tripathi Y. Effect of isometric handgrip exercise training on resting blood pressure in normal healthy adults. J Clin Diagn Res. 2014;8(9):BC08-10.

104. Mortensen $\mathrm{KH}$, Jones A, Steeden JA, Taylor AM, Muthurangu V. Isometric stress in cardiovascular magnetic resonance-a simple and easily replicable method of assessing cardiovascular differences not apparent at rest. Eur Radiol. 2016;26(4):1009-17.

105. Weiss RG, Bottomley PA, Hardy CJ, Gerstenblith G. Regional myocardial metabolism of high-energy phosphates during isometric exercise in patients with coronary artery disease. N Engl J Med. 1990;323(23):1593-600.

106. Conway MA, Bristow JD, Blackledge MJ, Rajagopalan B, Radda GK. Cardiac metabolism during exercise in healthy volunteers measured by 31P magnetic resonance spectroscopy. Br Heart J. 1991;65(1):25-30.

107. Hudsmith LE, Tyler DJ, Emmanuel Y, Petersen SE, Francis JM, Watkins $H_{\text {, }}$ et al. (31) P cardiac magnetic resonance spectroscopy during leg exercise at 3 tesla. Int J Card Imaging. 2009;25(8):819-26.

108. Dass S, Cochlin LE, Suttie JJ, Holloway CJ, Rider OJ, Carden L, et al. Exacerbation of cardiac energetic impairment during exercise in hypertrophic cardiomyopathy: a potential mechanism for diastolic dysfunction. Eur Heart J. 2015;36(24):1547-54.

109. Levelt E, Rodgers CT, Clarke WT, Mahmod M, Ariga R, Francis JM, et al. Cardiac energetics, oxygenation, and perfusion during increased workload in patients with type 2 diabetes mellitus. Eur Heart J. 2016;37(46):3461-9.

110. Nakamori S, Fahmy A, Jang J, El-Rewaidy H, Neisius U, Berg S, et al. Changes in myocardial native $\mathrm{T} 1$ and T2 after exercise stress: a noncontrast CMR pilot study. JACC Cardiovasc Imaging. 2020;13(3):667-80.

111. Globits S, Sakuma H, Shimakawa A, Foo TK, Higgins CB. Measurement of coronary blood flow velocity during handgrip exercise using breath-hold velocity encoded cine magnetic resonance imaging. Am J Cardiol. 1997; 79(2):234-7.

112. Hays AG, Hirsch GA, Kelle S, Gerstenblith G, Weiss RG, Stuber M. Noninvasive visualization of coronary artery endothelial function in healthy subjects and in patients with coronary artery disease. J Am Coll Cardiol. 2010;56(20):1657-65.

113. Hays AG, Stuber M, Hirsch GA, Yu J, Schar M, Weiss RG, et al. Non-invasive detection of coronary endothelial response to sequential handgrip exercise in coronary artery disease patients and healthy adults. PLoS One. 2013;8(3): e58047

114. Hays AG, lantorno M, Soleimanifard S, Steinberg A, Schar M, Gerstenblith G, et al. Coronary vasomotor responses to isometric handgrip exercise are primarily mediated by nitric oxide: a noninvasive MRI test of coronary endothelial function. Am J Physiol Heart Circ Physiol. 2015;308(11):H1343-50.

115. Dall'Armellina E, Baugh MB, Morgan TM, Hamilton CA, Tan P, Herrington DM, et al. Cardiovascular magnetic resonance measurement of coronary arterial blood flow at rest and after submaximal exercise. J Comput Assist Tomogr. 2006;30(3):421-5.

116. Puntawangkoon C, Morgan TM, Herrington DM, Hamilton CA, Hundley WG. Submaximal exercise coronary artery flow increases in postmenopausal women without coronary artery disease after estrogen and atorvastatin. Menopause. 2010;17(1):114-20.

117. Roest AA, Helbing WA, Kunz P, van den Aardweg JG, Lamb HJ, Vliegen HW, et al. Exercise MR imaging in the assessment of pulmonary regurgitation and biventricular function in patients after tetralogy of fallot repair. Radiology. 2002;223(1):204-11.
118. Lurz P, Muthurangu V, Schuler PK, Giardini A, Schievano S, Nordmeyer J, et al. Impact of reduction in right ventricular pressure and/or volume overload by percutaneous pulmonary valve implantation on biventricular response to exercise: an exercise stress real-time CMR study. Eur Heart J. 2012;33(19):2434-41.

119. Khiabani RH, Whitehead KK, Han D, Restrepo M, Tang E, Bethel J, et al. Exercise capacity in single-ventricle patients after Fontan correlates with haemodynamic energy loss in TCPC. Heart. 2015;101(2):139-43.

120. Tang E, Wei ZA, Whitehead KK, Khiabani RH, Restrepo M, Mirabella $L$, et al. Effect of Fontan geometry on exercise haemodynamics and its potential implications. Heart. 2017;103(22):1806-12.

121. Habert P, Bentatou Z, Aldebert P, Finas M, Bartoli A, Bal L, et al. Exercise stress CMR reveals reduced aortic distensibility and impaired rightventricular adaptation to exercise in patients with repaired tetralogy of Fallot. PLoS One. 2018;13(12):e0208749.

122. Houlind K, Stenbog EV, Sorensen KE, Emmertsen K, Hansen OK, Rybro L, et al. Pulmonary and caval flow dynamics after total cavopulmonary connection. Heart. 1999;81(1):67-72.

123. Fogel MA, Weinberg PM, Rychik J, Hubbard A, Jacobs M, Spray TL, et al. Caval contribution to flow in the branch pulmonary arteries of Fontan patients with a novel application of magnetic resonance presaturation pulse. Circulation. 1999;99(9):1215-21.

124. Stern H, Calavrezos L, Meierhofer C, Steinlechner E, Muller J, Hager A, et al. Physical exercise reduces aortic regurgitation: exercise magnetic resonance imaging. JACC Cardiovasc Imaging. 2014;7(3):314-5.

125. Roberts PA, Lin ACW, Cowan BR, Young AA, Stewart R. Comparison of effects of losartan and metoprolol on left ventricular and aortic function at rest and during exercise in chronic aortic regurgitation. Int J Card Imaging. 2018;34(4):615-24.

126. Kuno S, Ogawa T, Katsuta S, Itai Y. In vivo human myocardial metabolism during aerobic exercise by phosphorus-31 nuclear magnetic resonance spectroscopy. Eur J Appl Physiol Occup Physiol. 1994;69(6):488-91.

127. Yabe T, Mitsunami K, Okada M, Morikawa S, Inubushi T, Kinoshita M. Detection of myocardial ischemia by 31P magnetic resonance spectroscopy during handgrip exercise. Circulation. 1994;89(4):1709-16.

128. Evanochko WT, Buchthal SD, den Hollander JA, Katholi CR, Bourge RC, Benza RL, et al. Cardiac transplant patients response to the (31) P MRS stress test. J Heart Lung Transplant. 2002;21(5):522-9.

129. Leme AM, Salemi VM, Parga JR, lanni BM, Mady C, Weiss RG, et al. Evaluation of the metabolism of high energy phosphates in patients with Chagas' disease. Arq Bras Cardiol. 2010;95(2):264-70.

130. Scheuermann-Freestone M, Madsen PL, Manners D, Blamire AM, Buckingham RE, Styles $P$, et al. Abnormal cardiac and skeletal muscle energy metabolism in patients with type 2 diabetes. Circulation. 2003;107(24):3040-6.

131. Myerson SG, d'Arcy J, Christiansen JP, Dobson LE, Mohiaddin R, Francis JM, et al. Determination of clinical outcome in mitral regurgitation with cardiovascular magnetic resonance quantification. Circulation. 2016;133(23): 2287-96.

132. Myerson SG, d'Arcy J, Mohiaddin R, Greenwood JP, Karamitsos TD, Francis JM, et al. Aortic regurgitation quantification using cardiovascular magnetic resonance: association with clinical outcome. Circulation. 2012;126(12):1452-60.

133. Penicka M, Vecera J, Mirica DC, Kotrc M, Kockova R, Van Camp G. Prognostic implications of magnetic resonance-derived quantification in asymptomatic patients with organic mitral regurgitation: comparison with Doppler echocardiography-derived integrative approach. Circulation. 2018;137(13): 1349-60.

134. Baumgartner H, Falk V, Bax JJ, De Bonis M, Hamm C, Holm PJ, et al. 2017 ESC/EACTS guidelines for the management of valvular heart disease. Eur Heart J. 2017;38(36):2739-91.

135. Crandon S, Elbaz MSM, Westenberg JJM, van der Geest RJ, Plein S, Garg P. Clinical applications of intra-cardiac four-dimensional flow cardiovascular magnetic resonance: a systematic review. Int J Cardiol. 2017;249:486-93.

136. Macdonald JA, Barton G, Beshish AG, Goss KN, Eldridge MW, Francois CJ, et al. Abstract \#0686: inefficient right heart function in preterm adults as shown with 4D flow MRI. Proc Intl Soc Mag Reson Med. 2018;26.

\section{Publisher's Note}

Springer Nature remains neutral with regard to jurisdictional claims in published maps and institutional affiliations. 